\title{
Patterns and Universals of Mate Poaching Across 53 Nations: The Effects of Sex, Culture, and Personality on Romantically Attracting Another Person's Partner
}

\author{
David P. Schmitt \\ Bradley University
}

\author{
and 121 Members of the International Sexuality Description Project
}

\begin{abstract}
As part of the International Sexuality Description Project, 16,954 participants from 53 nations were administered an anonymous survey about experiences with romantic attraction. Mate poachingromantically attracting someone who is already in a relationship-was most common in Southern Europe, South America, Western Europe, and Eastern Europe and was relatively infrequent in Africa, South/Southeast Asia, and East Asia. Evolutionary and social-role hypotheses received empirical support. Men were more likely than women to report having made and succumbed to short-term poaching across all regions, but differences between men and women were often smaller in more gender-egalitarian regions. People who try to steal another's mate possess similar personality traits across all regions, as do those who frequently receive and succumb to the poaching attempts by others. The authors conclude that human mate-poaching experiences are universally linked to sex, culture, and the robust influence of personal dispositions.
\end{abstract}

When people feel romantic desire toward another person, they often act in special ways in hopes of attracting that person. They might try to enhance their appearance by wearing attractive clothes, engage in a lively conversation and try to present themselves in a positive light, or make an attempt at derogating the romantic competition in order to improve their relative standing (Schmitt \& Buss, 1996; Tooke \& Camire, 1991). Occasionally, the romantic competition has a decided head start. The desired partner may be regularly dating another person or have just embarked on a new romantic relationship. The object of affection may be married, recently engaged, or currently living with a partner. Trying to attract someone who is already in a romantic relationship is known as the process of mate poaching (Schmitt \& Buss, 2001), and it is a process filled with many special challenges and potential pitfalls.

David P. Schmitt, Department of Psychology, Bradley University, and 121 members of the International Sexuality Description Project. A complete list of the coauthors, listed alphabetically, can be found at the end of this article.

We thank Susan Sprecher (United States of America), Del Paulhus (Canada), Glenn D. Wilson (England), Qazi Rahman (England), Tamio Imagawa (Japan), Minoru Wada (Japan), Junichi Taniguchi (Japan), and Yuji Kanemasa (Japan) for helping with data collection and for contributing significantly to the samples used in this study. In addition, we acknowledge the work of Vijai N. Giri (India), Hmoud Olimat (Jordan), Mithila B. Sharan (India), and Robin Taylor (Fiji), who were part of the International Sexuality Description Project but did not collect information on human mate poaching. Finally, we thank Robert Fowler, Trisha Pasdach, and Andrea Kittell for their comments on an earlier version of this article.

Correspondence concerning this article should be addressed to David P. Schmitt, Department of Psychology, Bradley University, Peoria, IL 61625. E-mail: dps@bradley.edu
One of the central challenges of mate poaching is that many of the more effective tactics in general romantic attraction seem to backfire in the context of mate poaching, especially those that involve derogating competitors (Schmitt \& Buss, 2001). Instead of using direct tactics, many mate poachers are forced to use indirect means of gaining romantic favor, such as giving furtive glances, slowly invading the target's social networks, and planting subtle seeds of dissatisfaction within the existing relationship. Some tactics appear to work well in regard to mate poaching, such as men's use of status and resource-related tactics (Schmitt, 2002). Almost all mate-poaching tactics must be used with caution, however. The use of openly flirtatious poaching tactics, for example, can stir the wrath of the person's current partner and likely would be seen as inappropriate by the larger community. Indeed, many people feel that the entire process of mate poaching is unethical at its core, especially those that have felt the sting of losing a romantic partner at the hands of a friend or colleague (Schmitt \& Buss, 2001).

Despite the prohibitive difficulties associated with mate poaching, recent evidence suggests that poaching does occur, with most people reporting that they have experienced poaching-related attraction in one form or another (Schmitt \& Buss, 2001). In practice, mate poaching often takes the form of a short-term sexual seduction. Short-term mate poachers seek to elicit only a brief adulterous desertion by the already-mated partner. At times, the mate poacher may desire a more enduring relationship defection, perhaps even the establishment of a new, long-term alliance with the mating target. In most cases, the short-term and long-term targets of mate poachers regard romantic attempts by prospective suitors as either mildly flattering or, at worst, unwelcome attention (Schmitt \& Buss, 2001). However, mate poaching also can result from active and explicit solicitations made by those sexually or 
emotionally unsatisfied with their current relationships (Glass \& Wright, 1985; Grosskopf, 1983). In these cases, it is the poaching targets themselves who actively seek out would-be poachers, either enticing a singular night of adulterous passion or safely securing a more permanent marital replacement (Schmitt \& Shackelford, 2003).

Whether short-term or long-term, unwelcome or solicited, mate poaching typically involves an intricate web of social deception, interpersonal conflict, and intense emotionality (Shackelford, 1997; Shackelford \& Buss, 1996; Shackelford, LeBlanc, \& Drass, 2000). Although much is known about romantic attraction, infidelity, and the emotion of betrayal in isolation (e.g., Buss, 2000; Moore, 1995; Tennov, 1999; Tooke \& Camire, 1991; Walters \& Crawford, 1994), only recently has there been a concerted effort to understand how each interacts within the unique context of mate poaching (Bleske \& Shackelford, 2001). Also at issue has been whether mate poaching is a distinct evolutionary strategy or whether poaching-related attraction simply follows from more general adaptive desires and basic human mating strategies (Schmitt \& Buss, 2001; Schmitt \& Shackelford, 2003).

In this article, we extend this line of research by examining the psychology of mate poaching from a cross-cultural perspective. We explore the patterns and universals of poaching experiences across 53 nations, representing five continents, 28 languages, and 12 islands. We identify the pancultural and region-specific traits associated with being a mate poacher and with being a popular target of mate poachers. We also test several evolutionary and social-role hypotheses about the effects of sex and culture on romantically attracting someone else's partner. We begin by reviewing what is known about the frequency of mate poaching.

\section{How Often Do People Engage in Mate Poaching?}

Schmitt and Buss (2001) argued that mate poaching has been a recurrent and perhaps frequent form of romantic attraction over human evolutionary history. Because behavior does not fossilize, it is difficult to know with absolute certainty whether, and to what extent, ancestral humans actually engaged in poaching. One useful window into our evolutionary past is to look at behavioral regularities among "traditional" cultures that still practice foraging (Brown, 1991; Cronk, 1999), the hunting-and-gathering lifestyle that was prevalent for $99 \%$ of human history (Lee \& Daly, 1999). Among foraging cultures that exist today, there is some evidence that mate poaching occurs relatively frequently. Marital infidelity rates, for example, tend to be considerable, with at least "occasional" extramarital sex taking place in over $70 \%$ of traditional cultures (Broude \& Greene, 1976). Schmitt and Buss (2001) suggested that many of these infidelities could be the result of strategic short-term mate poaches. Among more developed societies, the occurrence rate of infidelity-defined as the percentage of people who have ever been unfaithful-is also appreciable and ranges from $20 \%$ to $75 \%$ depending on age, type of relationship, and relationship duration (Blumstein \& Schwartz, 1983; Thompson, 1983; Wiederman, 1997). Infidelity prevalence rates—such as the percentage of people who have been unfaithful in the past year-must by definition be somewhat lower than occurrence rates but are still considerable, ranging between $10 \%$ and $25 \%$ (Blumstein \& Schwartz, 1983; Laumann, Gagnon, Michael, \& Michaels, 1994). Infidelity rates such as these are observed despite the fact that extramarital sex within modern societies is usually met with more social disapproval than it is within most foraging cultures (Frayser, 1985; Pasternak, Ember, \& Ember, 1997).

Another window into the historical occurrence and prevalence of short-term mate poaching is to look at the reproductive consequences of infidelity. Studies of cuckoldry rates-the rates at which men are deceived into raising offspring that are genetically not their own-range from $0.7 \%$ (i.e., Switzerland; see Sasse, Müller, Chakraborty, \& Ott, 1994) to around 30\% (i.e., southeast England; see Philipp, 1973), though most estimates place the value between $10 \%$ and $15 \%$ in modern populations (see Cerda-Flores, Barton, Marty-Gonzalez, Rivas, \& Chakraborty, 1999; Macintyre \& Sooman, 1991). Cuckoldry rates are somewhat lower among the foraging cultures that have been studied, ranging between $2 \%$ and 9\% around the world (see Baker \& Bellis, 1995; Neel \& Weiss, 1975). Cuckoldry rates of this magnitude suggest that short-term poaching likely pays some reproductive dividends and has done so throughout human's foraging past. Alongside other evidence indicating that short-term mating and sperm competition are integral parts of the basic human mating system (Barash \& Lipton, 2001; Birkhead, 2000; Schmitt, Shackelford, \& Buss, 2001; Shackelford \& LeBlanc, 2001; Shackelford et al., 2002; Smith, 1984), it seems a plausible scenario that short-term mate poaching occurred with some regularity during our ancestral past.

There is reason to suspect that long-term mate poaching also occurred throughout human evolutionary history. Schmitt and Buss (2001) speculated that spousal deaths caused by warfare, birthing difficulties, and sickness-common occurrences in foraging cultures-would have produced a recurring need for people to remarry during their adult lifetimes. Because many of the most valuable partners already would be mated, the process of reentering the mating market for many people would have meant trying to attract and retain someone who was already mated. The reproductive advantages to those willing and able to woo away another's partner in these instances may have been considerable. Moreover, because most cultures include an equal number of men and women, the mating system of polygyny (i.e., the predominant system of foraging people whereby some men have more than one wife; Foley, 1996; Frayser, 1985) would have exacerbated the problem of finding a long-term mate for many men, forcing some men to perhaps engage in long-term mate poaching as a necessary sexual strategy. The human tendency toward serial monogamythe cyclical practice of marriage, divorce, and remarriage (Fisher, 1987) — would have provided further reproductive opportunities to those capable of poaching away the most valuable mates.

Although both theoretical rationale (e.g., adaptive problems of widowhood, polygyny, and sperm competition) and indirect pieces of evidence (e.g., infidelity, cuckoldry, and remarriage rates) suggest that poaching has been-and continues to be-a recurrent form of human mating, the direct evidence of short-term and long-term mate poaching is limited. On the basis of responses from a small sample of American college students, Schmitt and Buss (2001) found that most people admit to having attempted to poach someone in the past, with men $(64 \%)$ more likely than women $(49 \%)$ to report having made short-term poaching forays. Similar poaching occurrence rates were found in an older community sample (60\% vs. $38 \%$ for men and women, respectively). Schmitt and Buss (2001) found that over $80 \%$ of both men and women reported that they or a past partner had received a poaching 
attempt. Subjective perceptions of poaching attempts made on oneself may be less veridical than self-reported attempts made by oneself, but it nevertheless seems clear that most people in the Schmitt and Buss (2001) study had experienced mate poaching in some form.

Schmitt and Buss (2001) also reported that nearly half of college-age men and women who had received a poaching attempt in the past admitted that they had "gone along" or succumbed to the mate poacher. Similar levels of infidelity occurrence were observed in the community sample. Revealing that one has been unfaithful is, of course, a highly undesirable admission. As a result, these are probably underestimates of the occurrence of true poaching successes.

Perhaps most compelling, Schmitt and Buss (2001) found that $15 \%$ of people currently in romantic relationships reported that their current relationship directly resulted from mate poaching, either because they poached their current mate or because they were poached into the relationship by their current mate. Because these rates are based only on people's current romantic partnerships, the actual occurrence rates of effective long-term mate poaching may be well above $15 \%$. Finally, around $3 \%$ of current relationships resulted from both partners having poached each other out of previous relationships, a comparatively infrequent form that may be termed the "copoached" relationship. Overall, the Schmitt and Buss (2001) study painted a portrait of human mating replete with poaching-related experiences.

Despite the high occurrence of mate poaching in the Schmitt and Buss (2001) study, it remains unknown whether such experiences are limited to a set of small and peculiar American samples-the Schmitt and Buss (2001) samples were limited to the Midwest region of the United States-or whether poaching-related attraction occurs with similar regularity across different cultures. Given the apparent frequency and functionality of mate poaching (as evidenced in studies of human infidelity, cuckoldry, and remarriage), an evolutionary psychology perspective might anticipate mate poaching to be universal across cultures. There is no reason to expect that poaching is the primary or most common form of mating for all people, but the potential adaptive advantages for individuals in certain situations to engage in mate poaching may have been large enough for mate poaching to have become a pancultural form of romantic attraction. Moreover, if mate poaching does exist across all cultures, an evolutionary perspective would be interested in whether mate poaching constitutes a distinct evolutionary strategy or whether mate poaching follows as a consequence of more generalized mating adaptations.

If mate poaching is a distinct strategy, it should show evidence of "special design" across cultures (Gangestad, 2001; Gaulin, 1997; Williams, 1966). For example, if there are theoretical reasons for expecting people within certain environmental situations (e.g., an unbalanced sex ratio) to functionally benefit from mate poaching, and people in those conditions are significantly more likely than others to try-and to succeed - at mate poaching, this would provide partial (though not complete) evidence that mate poaching might be a distinct mating strategy. Such evidence could indicate that humans have psychological adaptations that take in specific information about the environment (both the physical environment and one's own personal characteristics) and then adjust mate-poaching behavior in functionally specific ways. Thus, just as possessing the personal attribute of physical attractiveness (e.g., high levels of bodily symmetry) may lead some men to functionally pursue a short-term mating strategy (Gangestad \& Simpson, 2000), being in a culture with an unbalanced sex ratio or possessing particular personality traits may functionally evoke mate-poaching behavior. We next review what is known about the specific personal characteristics of mate poachers.

\section{What Type of Person Engages in Mate Poaching?}

Schmitt and Buss (2001) found in American samples that people who more frequently attempt to poach another's romantic partner scored higher on certain personality trait scales. Using a measure of the Big Five dimensions of personality (Goldberg, 1992) and the Sexy Seven dimensions of sexuality (Schmitt \& Buss, 2000), Schmitt and Buss (2001) found that mate poachers described themselves as especially disagreeable, unconscientious, unfaithful, and erotophilic (see Fisher, Byrne, White, \& Kelley, 1988). Schmitt and Buss (2001) speculated that the lack of empathy associated with disagreeableness (Graziano \& Eisenberg, 1997) and the immorality associated with low conscientiousness (Hogan \& Ones, 1997) were key ingredients in the causal etiology of poaching, perhaps serving as psychological "releasing factors" for mate-poaching attempts (see also, Foster, Shrira, Campbell, \& Stone, 2002).

People who were especially successful at mate poaching in the Schmitt and Buss (2001) study also scored high on certain personality-trait scales. Those who reported success at poaching described themselves as relatively open to new experiences and reported being sexually attractive, relationally unfaithful, sexually unrestrained (not celibate), and erotophilic. The finding that successful mate poachers find it comfortable to talk about sex (i.e., high erotophilia) suggests that open conversations and curiosity about sexual matters may be a key milieu for successful matepoaching endeavors.

People who frequently received mate-poaching attempts (i.e., those that are common targets of poaching) also possessed certain traits. Schmitt and Buss (2001) found that frequent targets of mate poachers described themselves as more extraverted, open to experience, attractive, unfaithful, and loving than other people did. The combination of extraversion and openness may provide a special opportunity to poachers, as already-mated partners who are highly social and open to new ideas would be more likely to interact with those who are looking to poach. The fact that attractive and loving people were common targets of poaching was unsurprising, given that these attributes are universally desired in potential mates (Buss, 1989). The finding that unfaithful people are common targets suggests that mate poachers are functionally selective in choosing to attract those who are likely to succumb to poaching forays.

People who have succumbed to poaching attempts (i.e., those who have been unfaithful) described themselves as disagreeable, unconscientious, neurotic, unfaithful, erotophilic, and unloving (Schmitt \& Buss, 2001). Similar to mate poachers, unfaithful people display a lack of empathy and morality in their personality, combined with high neuroticism and erotophilia. Again, the finding that both successful mate poachers and those who are successfully poached find it comfortable to talk about sex (i.e., high erotophilia) suggests that curiosity and openness about sexual 
matters are potential catalysts for successful mate-poaching endeavors.

\section{How Important Is Culture to Mate Poaching?}

The studies and findings reported thus far-mate-poaching frequencies, sex differences in mate poaching, and personality traits of poachers and poaching targets-were primarily based on responses from college students in the United States. We attempted to replicate these findings across 10 major regions of the world using multiple college student and community samples from 53 individual nations. The 10 world regions were North America (represented by 3 nations), South America (5 nations), Western Europe (8 nations), Eastern Europe (11 nations), Southern Europe (6 nations), the Middle East (3 nations), Africa (7 nations), Oceania (2 nations), South/Southeast Asia (4 nations), and East Asia (4 nations). In addition to replicating the features of mate-poaching psychology identified in previous research (Schmitt \& Buss, 2001), we tested four hypotheses about patterns and universals of mate poaching across world regions.

\section{Hypothesis 1}

Our first hypothesis was as follows: Proportionately more men than women will attempt and succumb to short-term mate poaching across all world regions; proportionately more women than men will receive and be successful at short-term mate poaching across all world regions. Sexual strategies theory (Buss \& Schmitt, 1993) postulates that sex differences in human reproductive biology have led to fundamental differences in men's and women's sexual psychology (see also Symons, 1979; Trivers, 1972). In particular, because men need not invest as much as women to produce viable offspring (women are minimally required to invest in gestation, placentation, and lactation), men can reap greater reproductive benefits than women can from mating with multiple partners. It is not the case that all men are indiscriminate maters at all times. Men can be very discriminating when choosing a longterm marriage partner, for example (Kenrick, Sadalla, Groth, \& Trost 1990), and many men choose long-term mating as their primary sexual strategy (Gangestad \& Simpson, 2000). However, sexual strategies theory further postulates that when men actively seek short-term mates, they do so with less discriminating tastes than women do and that, on average, men will spend more effort seeking short-term mates than women will (see also Schmitt \& International Sexuality Description Project, 2003).

To understand the adaptive value of multiple mating for men, consider that 1 man can produce as many as 100 offspring by indiscriminately mating with 100 women in a given year, whereas a man who is monogamous will tend to produce only 1 child during that same time period. In contrast, whether a woman mates indiscriminately with 100 men or more reservedly with 1 man, she will still tend to produce only 1 child in a given year. This profound reproductive difference in the potential benefits of promiscuous or indiscriminate sex leads to the hypothesis that men, more than women, will seek multiple mates. Short-term mate poaching would help to achieve this fundamental adaptive goal of men's short-term mating strategy, and so men are predicted to attempt more short-term mate poaches than women; and when in a relationship, men are predicted to succumb more often to shortterm mate poaches on themselves.

Sexual strategies theory (Buss \& Schmitt, 1993) makes it clear that women can reap adaptive benefits from occasional short-term mating (see also Gangestad, 2001; Greiling \& Buss, 2000; Hrdy, 1981). However, women's short-term sexual strategy appears to be focused more on selectively obtaining men of high status and genetic quality rather than obtaining numerous partners in high quantity (Gangestad \& Thornhill, 1997; Schmitt, Shackelford, Duntley, Tooke, \& Buss, 2001; Smith, 1984). Because men will attempt more short-term mate poaching, it is also predicted that women will report receiving more short-term mate-poaching attempts. Also, because men will succumb more to short-term poaching, it is predicted that women will report more success in their short-term poaching attempts.

\section{Hypothesis 2}

Our second hypothesis was as follows: World regions with more demanding environments will have lower rates of short-term mate poaching. According to strategic pluralism theory (Gangestad \& Simpson, 2000), humans possess a menu of alternative mating strategies (see also, Belsky, 1999; Chisholm, 1996; Gross, 1996; Thiessen, 1994). Which strategy is followed depends in part on local environmental conditions. When local environments are demanding and the difficulties of rearing offspring are high, for example, the adaptive need for biparental care increases. Because both men and women are needed to raise offspring successfully in more demanding environments, Gangestad and Simpson (2000) argued that the importance of fidelity and heavy family investment should correspondingly increase in such environments. "In environments where male parenting qualities are needed and valued, women should be less likely to engage in short-term mating and extra-pair mating. In response to this, men should devote greater effort to parental investment" (Gangestad \& Simpson, 2000, p. 585). If true, this suggests that in cultures with more demanding environments (e.g., fewer resources), rates of short-term mate poaching — an index of infidelity — should be lower. Conversely, in cultures with abundant resources, short-term mate poaching should be more common in both occurrence and prevalence.

\section{Hypothesis 3}

Our third hypothesis was as follows: World regions with more men than women will have higher rates of mate poaching by men, whereas regions with more women than men will have higher rates of mate poaching by women. Operational sex ratio can be defined as the relative number of men to women in the local mating pool (Guttentag \& Secord, 1983; Pedersen, 1991). In most cultures, women tend to slightly outnumber men because of men's higher mortality rate (Daly \& Wilson, 1988). Nevertheless, significant variation exists in sex ratios across cultures and within cultures when viewed over historical time (Guttentag \& Secord, 1983).

According to Pedersen (1991), when men tend to outnumber women, women become a more valued resource over which men compete with greater-than-average intensity (see also Guttentag \& Secord, 1983). When the number of women noticeably outsizes the number of men, on the other hand, women become more competitive over access to the relatively scarce presence of the male 
Table 1

Sample Sizes, Sampling Type, Language of Survey, and Survey Design Across 53 Nations of the International Sexuality Description Project

\begin{tabular}{|c|c|c|c|c|c|}
\hline \multirow[b]{2}{*}{ Nation and region } & \multicolumn{2}{|c|}{$N$} & \multirow[b]{2}{*}{ Sample type } & \multirow[b]{2}{*}{ Language } & \multirow[b]{2}{*}{ Design } \\
\hline & Men & Women & & & \\
\hline North America & 1,470 & 2,553 & & & \\
\hline Canada & 368 & 662 & College students & English/French & Mixed \\
\hline Mexico & 105 & 108 & Community based & Spanish & Within \\
\hline United States of America & 997 & 1,783 & College students & English & Mixed \\
\hline South America & 445 & 591 & & & \\
\hline Argentina & 110 & 136 & College students & Spanish & Short-term \\
\hline Bolivia & 92 & 89 & College students & Spanish & Between \\
\hline Brazil & 42 & 55 & College students & Portuguese & Within \\
\hline Chile & 99 & 211 & College students & Spanish & Mixed \\
\hline Peru & 102 & 100 & College students & Spanish & Between \\
\hline Western Europe & 1,084 & 1,862 & & & \\
\hline Austria & 206 & 260 & College/community & German & Between \\
\hline Belgium (Flanders) & 165 & 354 & College students & Dutch (Flemish) & Within \\
\hline Finland & 32 & 89 & Community based & Finnish & Short-term \\
\hline France & 58 & 71 & College students & French & Within \\
\hline Germany & 288 & 491 & College/community & German & Between \\
\hline Netherlands & 115 & 126 & College students & Dutch & Between \\
\hline Switzerland & 84 & 126 & College students & German & Between \\
\hline United Kingdom & 136 & 345 & College/community & English & Mixed \\
\hline Eastern Europe & 1,207 & 1,550 & & & \\
\hline Croatia & 113 & 109 & College students & Croatian & Between \\
\hline Czech Republic & 105 & 129 & College students & Czech & Within \\
\hline Estonia & 78 & 107 & College students & Estonian & Short-term \\
\hline Latvia & 90 & 103 & College students & Latvian & Between \\
\hline Lithuania & 47 & 47 & College students & Lithuanian & Between \\
\hline Poland & 302 & 526 & College students & Polish & Long-term \\
\hline Romania & 122 & 126 & College students & Romanian & Between \\
\hline Serbia & 100 & 100 & College students & Serbian & Short-term \\
\hline Slovakia & 84 & 99 & College students & Slovak & Within \\
\hline Slovenia & 67 & 104 & College students & Slovenian & Between \\
\hline Ukraine & 100 & 100 & College/community & Ukrainian & Between \\
\hline Southern Europe & 497 & 836 & & & \\
\hline Cyprus & 23 & 36 & College students & Greek & Between \\
\hline Greece & 47 & 182 & College students & Greek & Between \\
\hline Italy & 92 & 108 & College/community & Italian & Between \\
\hline Malta & 131 & 190 & College students & English & Short-term \\
\hline Portugal & 110 & 142 & College students & Portuguese & Between \\
\hline Spain & 94 & 178 & College students & Spanish & Between \\
\hline Middle East & 503 & 552 & & & \\
\hline Israel & 177 & 211 & College students & Hebrew & Within \\
\hline Lebanon & 121 & 136 & College students & English & Long-term \\
\hline Turkey & 205 & 205 & College/community & Turkish & Mixed \\
\hline Africa & 684 & 548 & & & \\
\hline Botswana & 97 & 116 & College students & English & Short-term \\
\hline Democratic Republic of Congo & 88 & 32 & College/community & French & Within \\
\hline Ethiopia & 139 & 95 & College/community & English & Short-term \\
\hline Morocco & 90 & 86 & College students & English & Between \\
\hline South Africa & 81 & 81 & College students & English & Within \\
\hline United Republic of Tanzania & 91 & 41 & College students & English & Short-term \\
\hline Zimbabwe & 98 & 97 & College students & English & Between \\
\hline Oceania & 315 & 446 & & & \\
\hline Australia & 199 & 288 & College students & English & Mixed \\
\hline New Zealand & 116 & 158 & College students & English & Between \\
\hline South/Southeast Asia & 300 & 359 & & & \\
\hline Bangladesh & 82 & 61 & College students & Bangla & Within \\
\hline Indonesia & 52 & 53 & College students & Indonesian & Within \\
\hline Malaysia & 47 & 87 & College students & Malay & Long-term \\
\hline Philippines & 119 & 158 & College students & English & Short-term \\
\hline
\end{tabular}


Table 1 (continued)

\begin{tabular}{lrrllll}
\hline & \multicolumn{2}{c}{$N$} & & \\
\cline { 2 - 3 } \multicolumn{1}{c}{ Nation and region } & Men & Women & & Sample type & Language & Design \\
\hline East Asia & 563 & 589 & & & \\
Hong Kong (China) & 100 & 101 & College students & English & Within \\
Japan & 156 & 101 & College students & Japanese & Within \\
Republic of Korea & 191 & 294 & College students & Korean & Within \\
Taiwan & 116 & 93 & College students & Mandarin & Within \\
$\quad$ Worldwide sample & 7,068 & 9,886 & Varied & 28 languages & Mixed \\
\hline
\end{tabular}

Note. The nations of Jordan, Fiji, and India also were a part of the International Sexuality Description Project (ISDP), but the mate-poaching measure was not administered to those samples. Most ISDP samples were composed of college students; some included members of the community. All samples were convenience samples. In several samples, a between-subjects design was used. Half the participants were administered the short-term version of the mate-poaching measure; the other half were administered the long-term version (indicated in the Design column by "Between"). Some samples were administered both short-term and long-term versions of the mate-poaching measure (indicated by "Within"). Some samples were administered only short-term or long-term formats. Finally, some nations contained a mix of assessment formats (indicated by "Mixed"). Further details on sampling methods within each culture are available from the authors.

gender. Because an excess of one sex would exacerbate the problem of finding a mate, the heightened intrasexual competition associated with imbalanced ratios may accentuate rates of mate poaching. In regions where men outnumber women, for example, men should report higher rates of mate-poaching attempts. In regions where women outnumber men, in contrast, women should report higher rates of mate-poaching attempts.

\section{Hypothesis 4}

Our fourth hypothesis was as follows: Sex differences in shortterm mate poaching should be larger in regions with traditional sex-role ideologies and smaller in regions with liberal sex-role ideologies (as indexed by women's political and economic equality). According to the social structural theory of Eagly and Wood (1999), men and women do not possess adaptations that are specifically designed to cause sex differences in sexuality, including short-term mating tendencies (see also Wood \& Eagly, 2002). Instead, Eagly and Wood (1999) assumed that humans have evolved the tendency to have different social structures for men and women and that any "differences in the minds of men and women arise primarily from experience and socialization" (p. 414) once in those different social roles. Thus, when men and women differ, it is because they have received dissimilar socialization experiences-particularly those experiences associated with a society's bifurcated social and gender roles (Eagly, 1987; Kasser \& Sharma, 1999; Maccoby, 1998).

The degree to which men and women are forced to inhabit dissimilar social roles, and eventually develop psychological differences, is something that can vary across cultures (see Williams $\&$ Best, 1990). From this social structural perspective, sex differences in short-term mate poaching - if they exist-are likely produced by social-role differences, especially the different economic and family tasks that men and women perform (Eagly \& Wood, 1999; Wood \& Eagly, 2002). This social structural perspective generates the following hypothesis: In regions where women are more socially restricted in terms of politics and economics, sex differences in short-term mate poaching should be larger. Within regions that possess more "modern" or progressive sex-role ide- ologies - where women have greater access to power and money and are able to make their own decisions-women are allowed to explore a wider array of roles. Both men and women enjoy less burdensome and gender-constraining social structures in regions with modern sex-role ideologies (Williams \& Best, 1990), and "when men and women occupy the same specific social role, sex differences ... tend to erode" (Eagly \& Wood, 1999, p. 413). Thus, sex differences in short-term mate poaching should be smaller, or perhaps even absent, in regions with more gender equality.

\section{Method}

\section{Samples}

The research reported in this article is a result of the International Sexuality Description Project (ISDP; Schmitt et al., in press), a collaborative effort of over 100 social, behavioral, and biological scientists. Fifty-six nations composed the full span of ISDP cultures. In 3 of these nations, mate-poaching experiences were not assessed (i.e., Fiji, India, and Jordan). The current data set included samples from 53 nations.

Collaborators were asked to administer an anonymous nine-page survey to at least 100 men and 100 women. Some nations, such as the United States and Canada, included many convenience samples, and so the national sample size was much larger than 200. As seen in Table 1, several national samples failed to reach the designated sample size of 100 men and 100 women. Because of the small sample sizes for several individual nations, and because individual nations used varying poaching assessment formats (see below), the 53 nations were collapsed into 10 basic world regions when conducting key statistical analyses. The 10 world regions included North America ( $N=1,470$ men, 2,553 women), South America ( $N=445$ men, 591 women), Western Europe $(N=1,084$ men, 1,862 women), Eastern Europe ( $N=1,207$ men, 1,550 women), Southern Europe ( $N=497$ men, 836 women), the Middle East ( $N=503$ men, 552 women), Africa $(N=684$ men, 548 women $)$, Oceania $(N=315$ men, 446 women $)$, South/Southeast Asia $(N=300$ men, 359 women), and East Asia $(N=563$ men, 589 women). For each world region, at least 200 participants (100 men and 100 women) were included, providing the necessary statistical power (when setting $\beta=.90, \alpha=.05$, and when looking for effects moderate in size; Cohen, 1988) for evaluating regional variation in sex differences. In addition, these 10 world regions have proven useful in 
previous studies of romantic attachment, sexual desire, and human mating strategies (Schmitt et al., in press; Schmitt \& ISDP, 2003), and nations within each region were, on average, more similar in mate poaching than between nations.

Participants in most samples were recruited as volunteers, some received course credit for participation, and others received a small monetary reward for participation. All samples were administered an anonymous self-report survey; most surveys were returned via sealed envelope or the usage of a drop-box. Return rates for college student samples were relatively high (around 95\%), although this number was lower in some cultures. Return rates for community samples were around $50 \%$. Further details on the sampling and assessment procedures within each of the world regions and national samples are provided elsewhere (Schmitt et al., in press; Schmitt \& ISDP, 2003) and are available from David P. Schmitt.

\section{Procedure}

All participants were provided with a brief description of the study, including the following written instructions.

This questionnaire is entirely voluntary. All your responses will be kept confidential and your personal identity will remain anonymous. No identifying information is requested on this survey, nor will any such information be added later to this survey. If any of the questions make you uncomfortable, feel free not to answer them. You are free to withdraw from this study at any time for any reason. This series of questionnaires should take about 20 minutes to complete. Thank you for your participation.

The full instructional set provided by each collaborator varied, however, and was adapted to fit the specific culture and type of sample. Details on incentives and cover stories used across samples are available from David P. Schmitt.

\section{Measures}

Translation procedures. Researchers from nations where English was not the primary language were asked to conduct a translation/backtranslation procedure and administer the ISDP measures in their native language. This process typically involved the primary collaborator translating the measures into the native language of the participants and then having a second bilingual person back-translate the measures into English. Differences between the original English and the back-translation were discussed, and mutual agreements were made as to the most appropriate translation. In general, this is regarded as more of an "etic" approach to cross-cultural psychology (Church, 2001). This procedure attempts to balance the competing needs of making the translation meaningful and naturally readable to the native participants, while preserving the integrity of the original measure and its constructs (Brislin, 1980).

As seen in Table 1, this process resulted in the survey being translated into 26 different languages. Samples from Ethiopia, Hong Kong, Morocco, and the Philippines were administered the survey in English, but certain terms and phrases were annotated to clarify what were thought to be confusing words for the participants. The translation of the ISDP survey into the Flemish dialect of Dutch used only a translation procedure, as this involved minor word-variant changes from the original Dutch. Pilot studies were conducted at several testing sites to clarify translation and comprehension concerns.

Demographic measure. Each sample was first presented with a demographic measure entitled Confidential Personal Information. This measure included questions about sex (male, female), age, sexual orientation (heterosexual, homosexual, bisexual), current relationship status (e.g., married, cohabiting, dating one person exclusively, not currently involved with anyone), and socioeconomic status (lower, lower middle, middle, upper middle, upper).
Mate-poaching inventory. All participants were presented with one of two versions of a questionnaire entitled Anonymous Romantic Attraction Survey or ARAS. The ARAS asked a series of questions about personal experiences with romantic attraction and mate poaching. One version of the ARAS asked about short-term mate attraction experiences (i.e., brief affairs, one-night stands), and the other version of the ARAS asked about long-term mating experiences (i.e., potential marital relationships). Each rating scale on the questionnaire asked participants to describe their experiences with a specific attraction behavior. For the frequency of attempting poaching behaviors, rating scale values ranged from 1 (never) to 7 (always). Intermediate values were labeled rarely, seldom, sometimes, frequently, and almost always. For the degree of success in mate poaching, rating scales ranged from 1 (not at all successful) to 7 (very successful). An intermediate value of 4 (moderately successful) also was provided. These particular frequency and degree anchors tend to maximize the intervallevel quality of rating-scale data (Spector, 1992).

Seven items from the ARAS were relevant to the present study. The first ARAS question asked about the frequency with which participants have attempted to mate poach: "Have you ever tried to attract someone who was already in a romantic relationship with someone else for a short-term sexual relationship with you?" The second question asked, "If you have tried to attract someone who was already in a relationship for a short-term sexual relationship with you, how successful have you been (if you have never tried, skip this question)?" The third question asked about the participants' experiences with others trying to take them away from past mating partners: "While you were in a romantic relationship, have others tried to attract you as a short-term sexual partner?" A fourth item asked, "While you were in a romantic relationship, if others attempted to obtain you as a short-term sexual partner, how successful have they been (if others have never tried, skip this question)?" As noted in Table 1, some participants received versions of the ARAS in which they were asked about these four items in the context of short-term poaching and some in the context of long-term mate poaching; in a few samples, participants received both short-term and long-term versions.

Finally, all participants were asked three questions about their current relationship status: (a) "Are you currently in a romantic relationship?" (b) "Are you in a romantic relationship right now with a partner whom you attracted away from someone else?" and (c) "Are you in a romantic relationship right now with a partner who attracted you away from someone else?" After all three questions, participants were asked to circle either a "Yes" or "No" option.

Personality traits. All samples were administered the Big Five Inventory (BFI) of personality traits (Benet-Martínez \& John, 1998). The 44item English BFI was constructed to allow quick and efficient assessment of five personality dimensions-Extraversion, Agreeableness, Conscientiousness, Neuroticism, and Openness (Benet-Martínez \& John, 1998) Example items from the BFI include: "I see myself as someone who is outgoing, sociable" (i.e., Extraversion), "I see myself as someone who is helpful and unselfish with others" (i.e., Agreeableness), "I see myself as someone who is a reliable worker"(i.e., Conscientiousness), "I see myself as someone who worries a lot" (i.e., Neuroticism), and "I see myself as someone who is curious about many different things" (i.e., Openness). Self-report ratings for each item were made on a scale from 1 (disagree strongly) to 5 (agree strongly). This self-report measure was used because of its ease of administration and its brevity and because it has proven useful for cross-language and cross-cultural research (Benet-Martínez \& John, 1998).

Sexuality attributes. Most samples were administered a measure of the "Sexy Seven" sexuality attributes (Schmitt \& Buss, 2000). The Sexy Seven Measure asks participants to rate themselves compared with others they know (using a 9-point scale, ranging from $1=$ extremely inaccurate to $9=$ extremely accurate) on a list of 67 sexually connotative adjectives. The Sexy Seven scales that are scored from these self-ratings include Sexual Attractiveness (including facets of beauty and seduction), Relationship 
Exclusivity (whether one is promiscuous and adulterous), Gender Orientation (masculinity and femininity), Sexual Restraint (abstinence and prudishness), Erotophilic Disposition (obscenity, indecency, and lust), Emotional Investment (love and romance), and Sexual Orientation (homosexuality and heterosexuality).

Archival measures. Several archival data sets were used in this article. Gross domestic product per capita (GDP) and the Gender Development Index (i.e., the degree to which men and women differ in the achievement of basic human capabilities, including health, longevity, education, and a decent standard of living) were obtained from the United Nations Development Programme (2001). National sex ratios and the percentage of women in government were obtained from the United Nations Statistics Division (2001).

\section{Results}

\section{Frequency of Mate Poaching Across Cultures}

The frequency of mate poaching was examined in multiple ways. We examined both the occurrence (i.e., has it ever happened?) and prevalence (i.e., how often has it happened?) of mate-poaching experiences. This included whether and to what extent one has attempted a mate poach, whether and to what extent one has been successful at mate poaching, whether and to what extent one has received a mate poach, and whether and to what extent one has succumbed to a past mate poach attempt. We present the complete profile of mate-poaching experiences for short-term and long-term poaching and for men and women, separately. For comparative purposes, the results in Tables 2-10 follow the basic analysis strategy used by Schmitt and Buss (2001).

Have you attempted to attract someone who was already in a relationship? Similar to Schmitt and Buss (2001), we first examined the occurrence of mate poaching through identifying the percentage of participants who responded above $1(1=$ never, $2=$ rarely, $3=$ seldom, $4=$ sometimes, etc.) to the ARAS item, "Have you ever tried to attract someone who was already in a romantic relationship with someone else for a short-term sexual relationship with you?" Using this categorization strategy, Schmitt and Buss (2001) found that approximately $60 \%$ of men and $40 \%$ of women reported having made at least some attempt at short-term mate poaching. As shown in Tables 2 and 3, this finding was replicated in the North American region (62.1\% for men, 39.9\% for women).

The occurrence of attempting a short-term mate poach was significantly higher for men than women across all regions, supporting Hypothesis 1. Table 2 displays the magnitude of sex differences in short-term poaching occurrence using the phi $(\phi)$ statistic. Sex differences are considered small if phi exceeds \pm 0.10 , moderate if phi exceeds \pm 0.30 , and large if phi exceeds \pm 0.50 (Cohen, 1988). For all world regions, sex differences in short-term mate-poaching attempts were small to moderate in magnitude, confirming the hypothesis that men expend more mating effort on short-term mateships than women do (Buss \& Schmitt, 1993; Schmitt \& ISDP, 2003).

Exceptions to the seemingly high occurrence of short-term poaching included the finding that only $29.5 \%$ of East Asian males had ever engaged in short-term poaching and that less than $30 \%$ of women from the Middle East, Africa, South/Southeast Asia, and East Asia reported having made a short-term poaching attempt. Overall, though, more than $50 \%$ of men and $30 \%$ of women from around the world responded above 1 on the short-term form of this scale. From these data, we conclude that most college-age men and around a third of college-age women across cultures have engaged in at least some short-term mate poaching.

We examined mean levels on this ARAS scale as an index of the prevalence of mate-poaching attempts. Using this analysis strategy (see Table 3), the prevalence of short-term mate poaching overall for men was $2.32(S D=1.47)$, whereas the average woman rated only $1.68(S D=1.10)$. This would suggest that most men "rarely to seldom" engage in short-term mate-poaching attempts, whereas most women average below "rarely" on this scale. Despite these relatively low averages, however, the mean level of short-term mate seeking for men was significantly higher than for women across all world regions, again supporting Hypothesis 1. We used the $d$ statistic to evaluate the magnitude of mean differences between men and women. Differences using the $d$ statistic are considered small if $d$ exceeds \pm 0.20 , moderate if $d$ exceeds \pm 0.50 , and large if $d$ exceeds \pm 0.80 (Cohen, 1988). The largest sex

Table 2

Occurrence of Short-Term or Long-Term Mate-Poaching Attempts Across 10 World Regions

\begin{tabular}{|c|c|c|c|c|c|c|c|c|}
\hline \multirow[b]{2}{*}{ World regions } & \multicolumn{4}{|c|}{$\begin{array}{l}\text { Have you ever attempted to poach } \\
\text { for short-term mating? }\end{array}$} & \multicolumn{4}{|c|}{$\begin{array}{l}\text { Have you ever attempted to poach } \\
\text { for long-term mating? }\end{array}$} \\
\hline & Men $(\%)$ & Women $(\%)$ & $\chi^{2}$ & $\phi$ & Men $(\%)$ & Women $(\%)$ & $\chi^{2}$ & $\phi$ \\
\hline North America & 62.1 & 39.9 & $124.15 * * *$ & .22 & 63.4 & 51.5 & $28.38 * * *$ & .12 \\
\hline South America & 70.3 & 38.2 & $58.80^{* * *}$ & .32 & 65.6 & 50.2 & $13.04 * * *$ & .15 \\
\hline Western Europe & 56.7 & 39.2 & $56.39 * * *$ & .17 & 56.2 & 46.0 & $15.39 * * *$ & .10 \\
\hline Eastern Europe & 66.6 & 41.9 & $93.23 * * *$ & .25 & 59.9 & 43.3 & $44.12 * * *$ & .17 \\
\hline Southern Europe & 64.3 & 35.5 & $70.67 * * *$ & .28 & 60.0 & 44.0 & $10.11 * * *$ & .16 \\
\hline Middle East & 52.0 & 27.1 & $45.31 * * *$ & .26 & 53.5 & 38.9 & $12.24 * * *$ & .15 \\
\hline Africa & 56.7 & 22.9 & $122.73 * * *$ & .37 & 63.4 & 28.7 & $47.84 * * *$ & .34 \\
\hline Oceania & 61.0 & 42.2 & $16.34 * * *$ & .19 & 49.8 & 42.3 & 3.56 & .08 \\
\hline South/Southeast Asia & 51.4 & 26.6 & $33.92 * * *$ & .26 & 38.9 & 17.4 & $22.04 * * *$ & .24 \\
\hline East Asia & 29.5 & 14.9 & $35.43 * * *$ & .18 & 47.4 & 33.5 & $19.50 * * *$ & .14 \\
\hline Worldwide sample & 56.9 & 34.9 & $545.73 * * *$ & .22 & 57.1 & 43.6 & $164.50 * * *$ & .13 \\
\hline
\end{tabular}

Note. Occurrence was operationally defined as scoring greater than 1 on a 1 (never) to 7 (frequently) scale. For $\phi,|.10|=$ small, $|.30|=$ moderate, and $|.50|=$ large.

$* * * p<.001$ 
Table 3

Prevalence of Short-Term or Long-Term Mate-Poaching Attempts Across 10 World Regions

\begin{tabular}{|c|c|c|c|c|c|c|c|c|c|c|c|c|}
\hline \multirow[b]{3}{*}{ World region } & \multicolumn{6}{|c|}{$\begin{array}{l}\text { How frequently do you attempt to poach } \\
\text { for short-term mating? }\end{array}$} & \multicolumn{6}{|c|}{$\begin{array}{l}\text { How frequently do you attempt to poach } \\
\text { for long-term mating? }\end{array}$} \\
\hline & \multicolumn{2}{|c|}{ Men } & \multicolumn{2}{|c|}{ Women } & \multirow[b]{2}{*}{$t$} & \multirow[b]{2}{*}{$d$} & \multicolumn{2}{|c|}{ Men } & \multicolumn{2}{|c|}{ Women } & \multirow[b]{2}{*}{$t$} & \multirow[b]{2}{*}{$d$} \\
\hline & $M$ & $S D$ & $M$ & $S D$ & & & $M$ & $S D$ & $M$ & $S D$ & & \\
\hline North America & 2.47 & 1.51 & 1.76 & 1.12 & $13.98 * * *$ & .47 & 2.63 & 1.44 & 2.08 & 1.24 & $7.26^{* * *}$ & .38 \\
\hline South America & 2.66 & 1.47 & 1.77 & 1.17 & $8.15 * * *$ & .61 & 2.48 & 1.28 & 1.92 & 1.13 & $4.92 * * *$ & .44 \\
\hline Western Europe & 2.20 & 1.34 & 1.73 & 1.10 & $8.34 * * *$ & .35 & 2.21 & 1.30 & 1.93 & 1.17 & $3.44 * * *$ & .21 \\
\hline Eastern Europe & 2.52 & 1.41 & 1.86 & 1.22 & $9.92 * * *$ & .47 & 2.40 & 1.44 & 1.90 & 1.20 & $6.64 * * *$ & .35 \\
\hline Southern Europe & 2.65 & 1.66 & 1.67 & 1.09 & $10.82 * * *$ & .60 & 2.35 & 1.40 & 1.86 & 1.20 & $3.79 * * *$ & .35 \\
\hline Middle East & 2.03 & 1.25 & 1.44 & 0.86 & $7.29^{* * * *}$ & .47 & 2.47 & 1.53 & 1.87 & 1.25 & $4.01 * * *$ & .39 \\
\hline Africa & 2.38 & 1.61 & 1.54 & 1.16 & $9.59 * * *$ & .53 & 2.69 & 1.57 & 1.51 & 1.09 & $5.42 * * *$ & .75 \\
\hline Oceania & 2.25 & 1.23 & 1.85 & 1.18 & $3.54 * * *$ & .32 & 2.14 & 1.33 & 2.11 & 1.31 & 0.20 & .02 \\
\hline South/Southeast Asia & 2.36 & 1.64 & 1.55 & 1.07 & $6.80 * * *$ & .50 & 2.04 & 1.57 & 1.48 & 1.03 & $2.53 * *$ & .36 \\
\hline East Asia & 1.68 & 1.27 & 1.26 & 0.74 & $6.73 * * *$ & .32 & 2.03 & 1.38 & 1.61 & 1.03 & $5.40 * * *$ & .30 \\
\hline Worldwide sample & 2.32 & 1.47 & 1.68 & 1.10 & $26.67 * * *$ & .43 & 2.42 & 1.42 & 1.94 & 1.21 & $13.19 * * *$ & .33 \\
\hline
\end{tabular}

Note. Prevalence was operationally defined as the mean on a scale ranging from 1 (never) to 7 (frequently). For $d,|.20|=$ small, $|.50|=$ moderate, and $|.80|=$ large

$* * p<.01 . * * * p<.001$.

differences in the prevalence of short-term poaching attempts were found in South America $(d=.61)$ and Southern Europe $(d=.60)$, the smallest occurred in South/Southeast Asia $(d=.32)$ and East Asia $(d=.32)$. Most regions exhibited sex differences close to the worldwide average $(d=.43)$. From these mean-level analyses, we conclude that among college-age men and women, there is a significant and moderately sized sex difference in the prevalence of seeking already-mated partners for short-term sexual experiences.

As noted earlier, some participants completed a long-term mating version of the ARAS. Schmitt and Buss (2001) found that around $55 \%$ of men and women reported that they had made at least some attempt at long-term mate poaching. As seen down the right-hand side of Table 2, similar percentages of long-term mate poaching were reported across every ISDP world region, although the rates were somewhat lower in South/Southeast Asia. Across all cultures, women's occurrence rates of long-term poaching (43.6\%) were slightly more frequent than short-term poaching $(34.9 \%)$, $\chi^{2}(1, N=9,883)=160.04, p<.001, \phi=.13$. This was not true for men. It is interesting to note that, although East Asian women were conspicuously low on short-term poaching (14.9\%), they were close to the overall average on long-term mate poaching $(33.5 \%)$.

As with the prevalence of short-term poaching attempts, the mean levels of long-term poaching were less than substantial. The average man rated $2.42(S D=1.42)$ on the $1-7$ frequency scale, and the average woman rated only $1.94(S D=1.21)$. This would suggest that most men "rarely to seldom" engage in long-term mate-poaching attempts, whereas women average just below "rarely" on this scale. It is interesting to note that the difference between the prevalence of women's short-term and long-term poaching attempts was significant, $t(9881)=10.87, p<.001, d=$ .22. The difference between men's short-term and long-term poaching attempts was one third the size, $t(7063)=2.77, p<.01$, $d=.07$. Most regions exhibited sex differences in long-term mate-poaching attempts close to the worldwide average $(d=.33)$, although in Oceania the difference was negligible $(d=.02)$ and in Africa the sex difference was large $(d=.75)$. From these meanlevel analyses, we conclude that among college-age men and women, there is a significant and small to moderately sized sex difference in the prevalence of seeking already-mated partners for long-term mating experiences.

Have you successfully attracted someone who was already in a relationship? A second point of interest was whether participants from each region had successfully attracted someone who was already in a relationship. We examined the occurrence of whether our participants had ever successfully mate poached by asking, "If you have tried to attract someone who was already in a relationship for a short-term sexual relationship with you, how successful have you been (if you have never tried, skip this question)?” Responses greater than 1 ( $1=$ not at all successful) were interpreted as indicating the participant had been at least somewhat successful at poaching away a past partner (again, some participants received the long-term version of this question).

The percentages in Table 4 are based only on the responses of people who have attempted a mate poach in the past. These data do not represent base-rates of infidelity or serial monogamy, per se. Rather, they represent the relative mate-poaching efficacy of those subgroups of men and women that have targeted mates for poaching in the past. Among North American men, for example, 62.1\% had attempted a short-term mate poach (see Table 2). According to Table $4,84.1 \%$ of those men who had attempted short-term poaching achieved some level of success. Thus, $52.2 \%$ of men in the ISDP North American sample (i.e., $84.1 \%$ of $62.1 \%$ ) had successfully engaged in short-term mate poaching. For women, about $33.7 \%$ admitted to having ever successfully engaged in a shortterm mate poach. Overall, there were few sex differences in the occurrence of successful short-term mate poaching.

We examined the mean levels on this ARAS scale as an index of the prevalence of short-term mate-poaching success. The average man rated $3.86(S D=1.94)$ on the $1-7$ frequency scale, and the average woman rated $4.38(S D=2.13)$ (see Table 5). This 
Table 4

Occurrence of Successful Short-Term or Long-Term Mate Poaching (Among Those Who Have Tried) Across 10 World Regions

\begin{tabular}{|c|c|c|c|c|c|c|c|c|}
\hline \multirow[b]{2}{*}{ World region } & \multicolumn{4}{|c|}{$\begin{array}{l}\text { Have you ever successfully attempted to poach } \\
\text { for short-term mating? }\end{array}$} & \multicolumn{4}{|c|}{$\begin{array}{l}\text { Have you ever successfully attempted to poach } \\
\text { for long-term mating? }\end{array}$} \\
\hline & $\operatorname{Men}(\%)$ & Women $(\%)$ & $\chi^{2}$ & $\phi$ & Men $(\%)$ & Women $(\%)$ & $\chi^{2}$ & $\phi$ \\
\hline North America & 84.1 & 84.5 & 0.03 & -.01 & 76.6 & 80.0 & 1.69 & -.04 \\
\hline South America & 85.8 & 79.4 & 2.26 & .08 & 86.5 & 72.3 & $9.32 * *$ & .18 \\
\hline Western Europe & 83.9 & 90.1 & $7.29 * *$ & -.09 & 81.1 & 82.4 & 0.17 & -.02 \\
\hline Eastern Europe & 87.1 & 83.1 & 2.45 & .06 & 87.3 & 85.0 & 0.72 & .03 \\
\hline Southern Europe & 84.6 & 85.6 & 0.08 & -.01 & 88.2 & 84.8 & 0.45 & .05 \\
\hline Middle East & 88.2 & 86.5 & 0.16 & .03 & 85.6 & 87.8 & 0.20 & -.03 \\
\hline Africa & 78.6 & 65.9 & $7.50 * *$ & .14 & 78.4 & 65.4 & 3.46 & .13 \\
\hline Oceania & 82.2 & 89.0 & 1.90 & -.10 & 73.1 & 83.5 & 3.42 & -.13 \\
\hline South/Southeast Asia & 76.7 & 67.6 & 2.03 & .10 & 67.7 & 67.9 & 0.00 & .00 \\
\hline East Asia & 70.5 & 72.2 & 0.08 & -.02 & 77.9 & 75.6 & 0.10 & .03 \\
\hline Worldwide sample & 83.2 & 83.3 & 0.01 & .00 & 80.9 & 80.8 & 0.01 & .00 \\
\hline
\end{tabular}

Note. The occurrence of poaching success was operationally defined as scoring greater than 1 on a 1 (not at all successful) to 7 (very successful) scale, only among those participants who reported having attempted a mate poach. For $\phi,|.10|=$ small, $|.30|=$ moderate, and $|.50|=$ large.

$* * p<.01$.

would suggest that most men and women who have attempted a short-term mate poach have been "moderately" successful at it. It is interesting to note that, in most cases, women were more successful than men at short-term mate poaching, although this difference was significant only in North America, Western Europe, Eastern Europe, and Oceania. An exception to this trend was found in Africa, where men reported higher success rates. Still, from these mean-level analyses, we conclude that there is a trend for the prevalence of successful short-term mate poaching to be higher in women than men. This trend may be seen as supporting Hypothesis 1 , in that women's greater effectiveness in short-term poaching may come as a result of men's greater interest in short-term mateships (Buss \& Schmitt, 1993; Schmitt \& ISDP, 2003).

The occurrence and prevalence of successful long-term mate poaching was similar to that of short-term poaching. However, in most cases, there were no sex differences in reports of long-term mate-poaching success. An exception to this trend was found in South America, where men reported a higher occurrence $(\phi=.18)$ and prevalence ( $d=.24$ ) of successful long-term mate poaching than women did. It is interesting to note that the difference between the prevalence of women's short-term and long-term poaching success was significant, $t(3602)=5.74, p<.001, d=.20$. The difference between men's short-term and long-term poaching success was insignificant and was one fourth the magnitude of the difference for women, $t(3838)=1.03, n s, d=.05$. From these mean-level analyses, we conclude that there is a trend for the occurrence and prevalence of successful long-term mate poaching to be similar in men and women, but for women success at short-term mate poaching is noticeably greater than success at long-term mate poaching.

Table 5

Prevalence of Successful Short-Term or Long-Term Mate Poaching (Among Those Who Have Tried) Across 10 World Regions

\begin{tabular}{|c|c|c|c|c|c|c|c|c|c|c|c|c|}
\hline \multirow[b]{3}{*}{ World region } & \multicolumn{6}{|c|}{$\begin{array}{l}\text { How frequently have you successfully attempted to poach } \\
\text { for short-term mating? }\end{array}$} & \multicolumn{6}{|c|}{$\begin{array}{l}\text { How frequently have you successfully attempted to } \\
\text { poach for long-term mating? }\end{array}$} \\
\hline & \multicolumn{2}{|c|}{ Men } & \multicolumn{2}{|c|}{ Women } & \multirow[b]{2}{*}{$t$} & \multirow[b]{2}{*}{$d$} & \multicolumn{2}{|c|}{ Men } & \multicolumn{2}{|c|}{ Women } & \multirow[b]{2}{*}{$t$} & \multirow[b]{2}{*}{$d$} \\
\hline & $M$ & $S D$ & $M$ & $S D$ & & & $M$ & $S D$ & $M$ & $S D$ & & \\
\hline North America & 4.02 & 1.95 & 4.64 & 2.16 & $-5.30 * * *$ & -.29 & 4.05 & 2.08 & 4.03 & 2.05 & 0.08 & .04 \\
\hline South America & 3.75 & 1.72 & 3.95 & 2.15 & -0.90 & -.09 & 3.79 & 1.71 & 3.32 & 1.96 & $2.10^{*}$ & .24 \\
\hline Western Europe & 3.91 & 1.96 & 4.80 & 1.93 & $-6.55 * * *$ & -.45 & 3.98 & 2.11 & 4.08 & 2.15 & -0.51 & -.05 \\
\hline Eastern Europe & 3.78 & 1.82 & 4.17 & 2.09 & $-2.73 * *$ & -.19 & 3.94 & 1.96 & 3.92 & 2.06 & 0.10 & .01 \\
\hline Southern Europe & 4.15 & 1.98 & 4.46 & 2.12 & -1.49 & -.15 & 3.80 & 1.75 & 4.10 & 2.14 & -1.03 & -.14 \\
\hline Middle East & 4.26 & 1.97 & 4.71 & 2.16 & -1.65 & -.21 & 4.04 & 1.78 & 3.96 & 1.88 & 0.30 & .05 \\
\hline Africa & 3.90 & 2.05 & 3.31 & 2.14 & $2.68 * *$ & .28 & 4.00 & 1.89 & 4.42 & 2.43 & -0.80 & -.17 \\
\hline Oceania & 3.89 & 2.09 & 4.80 & 1.94 & $-3.25 * * *$ & -.44 & 3.64 & 2.16 & 4.35 & 2.09 & -1.87 & -.33 \\
\hline South/Southeast Asia & 3.33 & 1.87 & 3.43 & 2.23 & -0.37 & -.05 & 2.95 & 1.86 & 2.84 & 1.80 & 0.20 & .06 \\
\hline East Asia & 2.97 & 1.77 & 3.16 & 1.76 & -0.80 & -.11 & 2.94 & 1.77 & 2.87 & 1.64 & 0.37 & .04 \\
\hline Worldwide sample & 3.86 & 1.94 & 4.38 & 2.13 & $-8.85^{* * *}$ & -.24 & 3.92 & 1.97 & 3.96 & 2.08 & -0.39 & -.01 \\
\hline
\end{tabular}

Note. Prevalence was operationally defined as the mean on a scale ranging from 1 (not at all successful) to 7 (very successful), only among those participants who reported having attempted a mate poach. For $d,|.20|=$ small, $|.50|=$ moderate, and $|.80|=$ large.

$* p<.05 . \quad * * p<.01 . \quad * * * p<.001$. 
Has anyone tried to attract you while you were already in a relationship? A third point of interest was whether participants from each region had experienced someone trying to poach them while they were in a past relationship. Responses greater than one $(1=$ never $)$ to the question, "While you were in a romantic relationship, have others ever attempted to obtain you away from your partner for a short-term sexual relationship?" indicated that the participant had at some point received a short-term matepoaching attempt. Schmitt and Buss (2001) found that nearly $80 \%$ of men and women had received a mate-poaching attempt. As seen in Table 6, the worldwide occurrence of receiving a mate-poaching attempt was about $70 \%$ for men and women from most world regions. These short-term poaching percentages appeared somewhat higher in Western cultures (e.g., the Americas and all of Europe) compared with African and Asian cultures.

Few sex differences were observed in the occurrence of receiving either short-term or long-term mate-poaching attempts. In Oceania, women were more likely than men to report receiving long-term poaching attempts, whereas in South/Southeast Asia men were more likely than women to report receiving long-term poaching attempts. Sex differences in receiving short-term matepoaching attempts were nonsignificant within regions, although the worldwide occurrence of receiving short-term poaching attempts was higher for women than for men. The failure to find sex differences in the reception of short-term poaching attempts within regions would seem to conflict with men's self-reported tendency to make more short-term poaching attempts. However, men are more likely, in general, to perceive sexual interest from the opposite sex (Abbey, 1982). This may be an adaptive vigilance that leads men to be hypersensitive to short-term mating possibilities (Haselton \& Buss, 2000). Consequently, men in this study may have subjectively overestimated the short-term poaching attempts made by women. At the same time, this particular perceptual bias would not necessarily lead men to overestimate the relatively objective rates at which they made short-term poaching forays. Thus, it is possible for men to accurately report higher rates than women do in making short-term poaching attempts, while men overestimate the short-term interest of women and report similar perceptions of receiving short-term poaching attempts.

We examined the mean levels on this ARAS scale as an index of the prevalence of receiving mate-poaching attempts. The average man rated $2.78(S D=1.55)$ and the average woman rated 2.98 $(S D=1.64), t(11181)=-6.39, p<.001, d=-.12$ (see Table $7)$. This would suggest that most men and women "rarely to seldom" receive short-term mate-poaching attempts. In contrast to occurrence rates, the prevalence of receiving short-term matepoaching attempts did display some sexual differentiation across regions. In most regions, women reported significantly higher prevalence rates of receiving short-term poaching attempts, supporting Hypothesis 1. Only in East Asia were men significantly more likely to report receiving short-term poaching attempts. As noted above, it was possible that women would not report receiving more short-term attempts, due in part to men's potential hypersensitivity to sexual interest by women (Haselton \& Buss, 2000). In addition, women from four world regions (North America, Western Europe, Middle East, and Oceania) reported higher prevalence rates of receiving long-term poaching attempts. From these mean-level analyses, we conclude that among college-age men and women, there is some evidence that women report receiving more attempts at mate poaching-particularly in the context of short-term poaching - than men do.

Have you succumbed to a mate-poaching attempt when someone tried to attract you away from a previous partner? We examined the occurrence of whether participants had ever been successfully poached from a past relationship by asking, "If others have attempted to obtain you as a short-term sexual partner, how successful have they been (if others have never tried, skip this question)?" Responses greater than $1(1=$ not at all successful $)$ were interpreted as indicating the participant had been at least somewhat successfully poached away from a past partner (again, some participants received the long-term version of this question). We chose this analysis strategy because it was used in a previous study in which $50 \%$ of men and $35 \%$ of women had succumbed to a short-term poaching attempt (Schmitt \& Buss, 2001). As seen in

Table 6

Occurrence of Receiving Short-Term or Long-Term Mate-Poaching Attempts Across 10 World Regions

\begin{tabular}{|c|c|c|c|c|c|c|c|c|}
\hline \multirow[b]{2}{*}{ World region } & \multicolumn{4}{|c|}{$\begin{array}{l}\text { Has anyone ever tried to poach you away } \\
\text { for short-term mating? }\end{array}$} & \multicolumn{4}{|c|}{$\begin{array}{l}\text { Has anyone ever tried to poach you away } \\
\text { for long-term mating? }\end{array}$} \\
\hline & Men $(\%)$ & Women (\%) & $\chi^{2}$ & $\phi$ & $\operatorname{Men}(\%)$ & Women $(\%)$ & $\chi^{2}$ & $\phi$ \\
\hline North America & 74.5 & 76.2 & 0.97 & -.02 & 71.9 & 75.4 & 3.12 & -.04 \\
\hline South America & 77.7 & 71.0 & 2.46 & .08 & 68.4 & 77.3 & 1.80 & -.10 \\
\hline Western Europe & 75.5 & 77.9 & 1.39 & -.03 & 67.4 & 70.6 & 1.76 & -.03 \\
\hline Eastern Europe & 75.3 & 77.1 & 0.64 & -.02 & 65.9 & 72.2 & 3.63 & -.07 \\
\hline Southern Europe & 77.0 & 76.4 & 0.05 & .01 & 72.6 & 72.2 & 0.01 & .01 \\
\hline Middle East & 72.3 & 73.5 & 0.14 & -.01 & 66.5 & 73.1 & 2.77 & -.07 \\
\hline Africa & 66.1 & 64.1 & 0.30 & .02 & 76.7 & 78.4 & 0.08 & -.02 \\
\hline Oceania & 77.2 & 76.6 & 0.03 & .01 & 61.4 & 74.2 & $11.48 * * *$ & -.14 \\
\hline South/Southeast Asia & 55.7 & 54.4 & 0.08 & .01 & 52.4 & 34.6 & $5.70 *$ & .18 \\
\hline East Asia & 39.9 & 37.0 & 1.01 & .03 & 44.9 & 47.7 & 0.76 & -.03 \\
\hline Worldwide sample & 69.1 & 71.3 & $5.91^{*}$ & -.02 & 64.6 & 69.7 & $20.94 * * *$ & -.05 \\
\hline
\end{tabular}

Note. Occurrence was operationally defined as scoring greater than 1 on a 1 (never) to 7 (frequently) scale. For $\phi,|.10|=$ small, $|.30|=$ moderate, and $|.50|=$ large

$* p<.05 . \quad * * * p<.001$. 
Table 7

Prevalence of Receiving Short-Term or Long-Term Mate-Poaching Attempts Across 10 World Regions

\begin{tabular}{|c|c|c|c|c|c|c|c|c|c|c|c|c|}
\hline \multirow[b]{3}{*}{ World region } & \multicolumn{6}{|c|}{$\begin{array}{l}\text { How frequently do people attempt to poach you away } \\
\text { for short-term mating? }\end{array}$} & \multicolumn{6}{|c|}{$\begin{array}{l}\text { How frequently do people attempt to poach you away } \\
\text { for long-term mating? }\end{array}$} \\
\hline & \multicolumn{2}{|c|}{ Men } & \multicolumn{2}{|c|}{ Women } & \multirow[b]{2}{*}{$t$} & \multirow[b]{2}{*}{$d$} & \multicolumn{2}{|c|}{ Men } & \multicolumn{2}{|c|}{ Women } & \multirow[b]{2}{*}{$t$} & \multirow[b]{2}{*}{$d$} \\
\hline & $M$ & $S D$ & $M$ & $S D$ & & & $M$ & $S D$ & $M$ & $S D$ & & \\
\hline North America & 3.05 & 1.61 & 3.19 & 1.66 & $-2.19^{*}$ & -.09 & 3.10 & 1.57 & 3.34 & 1.58 & $-2.56^{* *}$ & -.15 \\
\hline South America & 3.04 & 1.49 & 2.84 & 1.60 & 1.47 & .12 & 2.83 & 1.57 & 2.68 & 1.39 & 1.06 & .09 \\
\hline Western Europe & 2.82 & 1.40 & 3.13 & 1.49 & $-4.46^{* * *}$ & -.20 & 2.72 & 1.38 & 3.08 & 1.44 & $-3.82 * * *$ & -.25 \\
\hline Eastern Europe & 2.80 & 1.41 & 3.07 & 1.52 & $-3.52 * * *$ & -.18 & 2.69 & 1.47 & 2.58 & 1.48 & 1.33 & .08 \\
\hline Southern Europe & 3.16 & 1.57 & 3.11 & 1.58 & 0.41 & .03 & 2.92 & 1.54 & 2.78 & 1.51 & 0.92 & .09 \\
\hline Middle East & 2.74 & 1.44 & 2.97 & 1.61 & $-1.93^{*}$ & -.14 & 2.80 & 1.56 & 3.19 & 1.66 & $-2.23^{*}$ & -.23 \\
\hline Africa & 2.87 & 1.72 & 3.15 & 1.98 & $-2.35^{*}$ & -.14 & 3.55 & 1.83 & 3.57 & 1.62 & -0.07 & -.01 \\
\hline Oceania & 2.84 & 1.45 & 3.20 & 1.59 & $-2.48 * *$ & -.22 & 2.93 & 1.50 & 3.35 & 1.37 & $-2.43^{*}$ & -.28 \\
\hline South/Southeast Asia & 2.54 & 1.65 & 2.50 & 1.69 & 0.28 & .03 & 3.55 & 1.75 & 3.85 & 1.66 & -0.93 & -.17 \\
\hline East Asia & 1.92 & 1.35 & 1.77 & 1.20 & $2.05^{*}$ & .12 & 1.96 & 1.33 & 2.00 & 1.27 & -0.44 & -.03 \\
\hline Worldwide sample & 2.78 & 1.55 & 2.98 & 1.64 & $-6.39 * * *$ & -.12 & 2.90 & 1.54 & 3.03 & 1.54 & $-3.03 * *$ & -.08 \\
\hline
\end{tabular}

Note. Prevalence was operationally defined as the mean on a scale ranging from 1 (never) to 7 (frequently). For $d,|.20|=$ small, $|.50|=$ moderate, and $|.80|=$ large.

$* p<.05$. $* * p<.01 . \quad * * * p<.001$.

Table 8 , around $60 \%$ of men and $45 \%$ of women worldwide reported that they had succumbed to a short-term mate poach at some point in their past. For long-term poaching, over $60 \%$ of men and $50 \%$ of women reported that they had succumbed to a poaching attempt at some point in their lives.

These percentages are based only on the responses of people who have received a mate-poaching attempt. These data do not represent base rates of infidelity or serial monogamy. Rather, they may represent the relative susceptibility of those subgroups of men and women that have been targeted by mate poachers. Among North American men, for example, $74.5 \%$ had received a shortterm mate-poaching attempt (see Table 6). According to Table 8, $63.3 \%$ of those men who have received an attempted short-term poach went along with it. Thus, $47.2 \%$ of men in the ISDP North
American sample (i.e., $63.3 \%$ of $74.5 \%$ ) had ever engaged in a short-term affair as a result of poaching. For women, about $32 \%$ admitted to having gone along with a short-term mate poach. These percentages are in line with other studies of infidelity among college-age individuals and dating couples from North America (see Wiederman, 1997; Wiederman \& Hurd, 1999).

The occurrence rates of going along with a short-term mate poach were significantly higher for men than women across all cultures, supporting Hypothesis 1 (see Table 8). For long-term poaching, men reported significantly more success in South America, Western Europe, Eastern Europe, Africa, Oceania, and South/ Southeast Asia. The primary difference between the occurrence of succumbing to short-term and long-term poaching was between women, with more women succumbing to long-term poaching

Table 8

Occurrence of Having Been Successfully Poached as a Short-Term or Long-Term Mate (Among Those Who Have Received Attempts) Across 10 World Regions

\begin{tabular}{|c|c|c|c|c|c|c|c|c|}
\hline \multirow[b]{2}{*}{ World region } & \multicolumn{4}{|c|}{$\begin{array}{l}\text { Has anyone ever successfully poached you away } \\
\text { for short-term mating? }\end{array}$} & \multicolumn{4}{|c|}{$\begin{array}{l}\text { Has anyone ever successfully poached you away } \\
\text { for long-term mating? }\end{array}$} \\
\hline & Men $(\%)$ & Women (\%) & $\chi^{2}$ & $\phi$ & Men (\%) & Women $(\%)$ & $\chi^{2}$ & $\phi$ \\
\hline North America & 63.3 & 42.1 & $78.94 * * *$ & .20 & 52.0 & 47.9 & 2.47 & .04 \\
\hline South America & 59.9 & 40.4 & $16.52 * * *$ & .19 & 64.9 & 55.7 & $3.76^{*}$ & .09 \\
\hline Western Europe & 66.1 & 56.2 & $13.45^{* * * *}$ & .10 & 68.5 & 58.5 & $10.97 * * *$ & .10 \\
\hline Eastern Europe & 62.8 & 48.5 & $22.57 * * *$ & .14 & 72.6 & 63.6 & $9.91 * *$ & .10 \\
\hline Southern Europe & 72.5 & 41.7 & $58.93 * * *$ & .30 & 67.7 & 61.8 & 1.17 & .06 \\
\hline Middle East & 66.8 & 44.1 & $24.53 * * *$ & .23 & 64.2 & 54.5 & 3.55 & .10 \\
\hline Africa & 55.1 & 26.9 & $50.11 * * *$ & .29 & 62.4 & 42.0 & $11.90 * * *$ & .20 \\
\hline Oceania & 58.5 & 44.9 & $6.20 * *$ & .13 & 57.2 & 44.7 & $6.17 * *$ & .12 \\
\hline South/Southeast Asia & 60.0 & 28.0 & $34.20 * * *$ & .32 & 59.8 & 46.8 & $4.46^{*}$ & .13 \\
\hline East Asia & 64.5 & 51.7 & $6.37 * *$ & .13 & 64.4 & 57.2 & 1.93 & .07 \\
\hline Worldwide sample & 63.2 & 45.0 & $248.82 * * *$ & .18 & 63.2 & 54.4 & $48.27 * * *$ & .09 \\
\hline
\end{tabular}

Note. The occurrence of poaching success was operationally defined as scoring greater than 1 on a 1 (not at all successful) to 7 (very successful) scale, only among those participants who reported having received a mate-poaching attempt. For $\phi,|.10|=$ small, $|.30|=$ moderate, and $|.50|=1$ large.

$* p<.05$. $* * p<.01$. $* * * p<.001$ 
(54.4\%) than short-term poaching $(45.0 \%), \chi^{2}(1, N=6,925)=$ 101.03, $p<.001, \phi=.12$.

We examined the mean levels on this ARAS scale as an index of the prevalence of succumbing to mate-poaching attempts. The average man rated $2.86(S D=1.91)$ and the average woman rated $2.10(S D=1.58), t(7867)=19.09, p<.001, d=.40$ (see Table 9). This suggests that most men who receive short-term poaching attempts "seldom" succumb to the poachers, whereas women "rarely" succumb when they receive short-term mate-poaching attempts. Within each of the 10 ISDP world regions, men reported significantly higher prevalence rates of succumbing to short-term mate-poaching attempts, again supporting Hypothesis 1. In longterm mate poaching, men were more likely to succumb only in Western Europe and Eastern Europe. From these mean-level analyses, we conclude that, among college-age men and women, there is evidence that men succumb to short-term poaching attempts more frequently than women do.

Is your current romantic relationship the result of mate poaching? When participants were asked about their current relationship status, over half of the men and women reported being in a romantic relationship. This is typical of college-student samples (e.g., Buss, Larsen, Westen, \& Semmelroth, 1992). Of those participants who reported that they were currently in a romantic relationship, around $12 \%$ of men and $8 \%$ of women reported that their current relationship resulted from their having attracted their current partner away from someone else (see Table 10). These data provide a relatively clear and direct estimate of recent long-term mate-poaching success, suggesting that around $10 \%$ of current relationships result from mate poaching.

We also asked whether participants had been lured away from a past partner into their current relationship. About $14 \%$ of women and $10 \%$ of men reported that they had been poached into their current romantic relationship. Finally, the percentage of relationships that resulted from both partners poaching each other into the relationship (i.e., a copoach) varied from a low of $1.7 \%$ in South America to a high of $7.7 \%$ in South/Southeast Asia.
On the basis of the current ISDP findings, we conclude that the occurrence of mate poaching is a cultural universal. Although the overall prevalence of mate poaching ranged from only "rarely" to "seldom," in every region of the world sampled by the ISDP, at least one-fifth of the sample had engaged in mate-poaching behavior, and most of those who attempted mate poaching had achieved at least some level of success. In addition, men universally reported succumbing to short-term mate poaches more than women did. Perhaps the most compelling testament to poaching frequency, however, was the finding that around $15 \%$ of people currently in a romantic relationship admitted that the relationship directly resulted from mate poaching - successful poaching either by oneself or on oneself. We turn next to the personal characteristics of mate poachers and their targets.

\section{Personal Characteristics and Mate-Poaching Experiences Across Cultures}

We related participants' recollections of poaching-attraction experiences to self-reported personal characteristics. Few differences emerged between short-term and long-term poaching correlations. In general, the relationships between personality and mate poaching were stronger in short-term poaching, but across both forms of poaching, the same set of personality and sexuality variables were involved. As a result, we focus on the relationship between personal characteristics and mate poaching after collapsing across temporal context. The results in Tables 11-15 represent partial correlations between mate poaching and personal characteristics, after controlling for the effects of nation within each world region. Nation was statistically controlled for in order to rule out any confounding influences within each region. If one nation had particularly high levels of both extraversion and mate poaching, for example, failing to control for nation would artificially produce a positive correlation between extraversion and mate poaching within the general world region.

Table 9

Prevalence of Having Been Successfully Poached as a Short-Term or Long-Term Mate (Among Those Who Have Received Attempts) Across 10 World Regions

\begin{tabular}{|c|c|c|c|c|c|c|c|c|c|c|c|c|}
\hline \multirow[b]{3}{*}{ World region } & \multicolumn{6}{|c|}{$\begin{array}{l}\text { How frequently have you been successfully poached } \\
\text { away for short-term mating? }\end{array}$} & \multicolumn{6}{|c|}{$\begin{array}{l}\text { How frequently have you been successfully poached away } \\
\text { for long-term mating? }\end{array}$} \\
\hline & \multicolumn{2}{|c|}{ Men } & \multicolumn{2}{|c|}{ Women } & \multirow[b]{2}{*}{$t$} & \multirow[b]{2}{*}{$d$} & \multicolumn{2}{|c|}{ Men } & \multicolumn{2}{|c|}{ Women } & \multirow[b]{2}{*}{$t$} & \multirow[b]{2}{*}{$d$} \\
\hline & $M$ & $S D$ & $M$ & $S D$ & & & $M$ & $S D$ & $M$ & $S D$ & & \\
\hline North America & 2.82 & 1.89 & 2.03 & 1.56 & $9.85 * * *$ & .42 & 2.54 & 1.70 & 2.39 & 1.71 & 1.26 & .08 \\
\hline South America & 2.82 & 1.96 & 1.89 & 1.45 & $5.68 * * *$ & .48 & 2.64 & 1.70 & 2.38 & 1.63 & 1.47 & .15 \\
\hline Western Europe & 2.91 & 1.89 & 2.43 & 1.69 & $4.95 * * *$ & .26 & 3.23 & 1.74 & 2.64 & 1.82 & $4.17 * * *$ & .30 \\
\hline Eastern Europe & 2.90 & 1.93 & 2.18 & 1.62 & $6.71 * * *$ & .37 & 3.26 & 1.94 & 2.95 & 2.02 & $2.19^{*}$ & .15 \\
\hline Southern Europe & 3.34 & 2.00 & 1.98 & 1.48 & $10.00 * * *$ & .68 & 2.80 & 1.70 & 3.02 & 2.09 & -0.96 & -.10 \\
\hline Middle East & 3.07 & 2.01 & 2.04 & 1.57 & $6.22 * * *$ & .52 & 2.76 & 1.69 & 2.62 & 1.85 & 0.64 & .08 \\
\hline Africa & 2.57 & 1.83 & 1.74 & 1.44 & $6.53 * * *$ & .45 & 2.75 & 1.78 & 2.24 & 1.70 & 1.61 & .29 \\
\hline Oceania & 2.65 & 1.81 & 2.25 & 1.75 & $2.07 *$ & .22 & 2.65 & 1.61 & 2.48 & 3.28 & 0.44 & .05 \\
\hline South/Southeast Asia & 2.86 & 1.96 & 1.65 & 1.23 & $6.65 * * *$ & .62 & 2.53 & 1.38 & 2.64 & 1.45 & -0.37 & -.07 \\
\hline East Asia & 2.74 & 1.77 & 2.11 & 1.45 & $3.75 * * *$ & .36 & 2.66 & 1.70 & 2.36 & 1.56 & 1.77 & .18 \\
\hline Worldwide sample & 2.86 & 1.91 & 2.10 & 1.58 & $19.09 * * *$ & .40 & 2.88 & 1.81 & 2.62 & 1.95 & $4.18 * * *$ & .13 \\
\hline
\end{tabular}

Note. Prevalence was operationally defined as the mean on a scale ranging from 1 (not at all successful) to 7 (very successful), only among those participants who reported having received a mate-poaching attempt. For $d,|.20|=$ small, $|.50|=$ moderate, and $|.80|=1$ arge.

$* p<.05$. $* * * p<.001$. 
Table 10

Percentage of Those Currently in Relationships Who Report That They Poached Their Current Partner, That They Were Poached by Their Current Partner, or That Both Occurred Simultaneously (a "Copoach") Across 10 World Regions

\begin{tabular}{|c|c|c|c|c|c|c|c|c|c|}
\hline \multirow[b]{2}{*}{ World region } & \multicolumn{4}{|c|}{$\begin{array}{l}\text { Did you poach your current partner } \\
\text { into your relationship? }\end{array}$} & \multicolumn{4}{|c|}{$\begin{array}{l}\text { Did your current partner poach you } \\
\text { into your relationship? }\end{array}$} & \multirow[b]{2}{*}{ Copoach? (\%) } \\
\hline & Men (\%) & Women $(\%)$ & $\chi^{2}$ & $\phi$ & Men $(\%)$ & Women $(\%)$ & $\chi^{2}$ & $\phi$ & \\
\hline North America & 10.4 & 7.7 & $8.45^{* *}$ & .05 & 10.8 & 13.6 & $6.59 * *$ & -.05 & 3.2 \\
\hline South America & 8.2 & 6.8 & 0.71 & .03 & 7.9 & 9.9 & 1.20 & -.04 & 1.7 \\
\hline Western Europe & 9.4 & 7.9 & 2.16 & .03 & 5.9 & 10.7 & $18.61 * * *$ & -.08 & 2.5 \\
\hline Eastern Europe & 17.8 & 11.7 & $18.66^{* * * *}$ & .09 & 11.2 & 20.0 & $35.30 * * *$ & -.12 & 4.3 \\
\hline Southern Europe & 10.3 & 7.6 & 2.79 & .05 & 11.0 & 12.6 & 0.74 & -.02 & 2.8 \\
\hline Middle East & 8.6 & 6.0 & 2.56 & .05 & 6.8 & 10.0 & 3.44 & -.06 & 2.9 \\
\hline Africa & 17.3 & 10.7 & $10.52 * * *$ & .09 & 17.7 & 18.0 & 0.01 & -.00 & 5.8 \\
\hline Oceania & 3.4 & 6.6 & 2.09 & -.07 & 4.0 & 9.9 & $5.22 *$ & -.11 & 1.9 \\
\hline South/Southeast Asia & 17.3 & 11.1 & $5.14 *$ & .09 & 12.1 & 15.9 & 1.90 & -.06 & 7.7 \\
\hline East Asia & 7.6 & 5.8 & 1.20 & .04 & 7.2 & 12.4 & $7.31 * *$ & -.09 & 3.3 \\
\hline Worldwide sample & 11.8 & 8.4 & $51.30 * * *$ & .06 & 9.9 & 13.6 & $50.72 * * *$ & -.06 & 3.4 \\
\hline
\end{tabular}

Note. Numbers reflect the percentage of people reporting "yes" to various questions. For $\phi,|.10|=$ small, $|.30|=$ moderate, and $|.50|=1$ large.

$* p<.05$. *** $p<.01$. **** $p<.001$.

What type of person tries to poach another's partner? We compared responses to the ARAS item, "Have you ever tried to attract someone who was already in a romantic relationship with someone else for a short-term sexual relationship with you?" with measures of personality traits and sexuality attributes that were deemed relevant to mate poaching in previous studies (Schmitt \& Buss, 2001; Schmitt \& Shackelford, 2003). All comparisons were between raw scores on continuous scales, and some participants received the long-term version of this scale. As displayed in Table 11, people who more often attempt mate poaching possess similar personality traits across regions. From a measure of the Big Five personality traits (Benet-Martínez \& John, 1998), mate poachers tended to describe themselves as extraverted and disagreeable. Extraversion, sometimes called surgency, is the degree to which one is active, assertive, and talkative (Ashton, Lee, \& Paunonen, 2002; Watson \& Clark, 1997). Agreeableness refers to whether one is generous, gentle, and empathetic (Graziano \& Eisenberg,
1997). Schmitt and Buss (2001) found that mate poachers also were low on conscientiousness - a trait linked to low morality and lack of will. This association was apparent, though somewhat less consistent, across the world regions of the ISDP.

From a measure of the Sexy Seven sexual dimensions (Schmitt \& Buss, 2000), Schmitt and Buss (2001) found that mate poachers described themselves as unfaithful and erotophilic. In the present ISDP study, mate poachers displayed these same sexual attributes. Indeed, these associations were strong and significant for both men and women across all world regions. Mate poachers were sexually unfaithful-apparently, they do not ask others to do what they would not do themselves. Mate poachers also were erotophilic, scoring high in lust, perversion, and indecency (Fisher et al., 1988; Schmitt \& Buss, 2000).

What type of person successfully poaches another person's partner? As displayed in Table 12, the psychological traits of people who reported that they have successfully poached away

Table 11

Are Men and Women Who More Frequently Attempt Mate Poaching More Extraverted, Disagreeable, Unconscientious, Unfaithful, and Erotophilic Than Others?

\begin{tabular}{|c|c|c|c|c|c|c|c|c|c|c|}
\hline \multirow[b]{2}{*}{ World region } & \multicolumn{2}{|c|}{ Extraversion } & \multicolumn{2}{|c|}{ Agreeableness } & \multicolumn{2}{|c|}{ Conscientiousness } & \multicolumn{2}{|c|}{$\begin{array}{l}\text { Relationship } \\
\text { exclusivity }\end{array}$} & \multicolumn{2}{|c|}{$\begin{array}{l}\text { Erotophilic } \\
\text { disposition }\end{array}$} \\
\hline & Men & Women & Men & Women & Men & Women & Men & Women & Men & Women \\
\hline North America & $.16^{* * * *}$ & $.07 * * *$ & $-.14 * * *$ & $-.16 * * *$ & $-.05 *$ & $-.10 * * *$ & $-.44 * * *$ & $-.31 * * *$ & $.31 * * *$ & $.27 * * *$ \\
\hline South America & $.16^{* *}$ & .05 & $-.12 *$ & $-.12 *$ & .01 & -.04 & $-.42 * * *$ & $-.23 * * *$ & $.23 * * *$ & $.21 * * *$ \\
\hline Western Europe & $.17 * * *$ & $.11 * * *$ & $-.11 * * *$ & $-.12 * * *$ & $-.09 * *$ & $-.05^{*}$ & $-.39 * * *$ & $-.36 * * *$ & $.30 * * *$ & $.26 * * *$ \\
\hline Eastern Europe & $.14 * * *$ & $.11 * * *$ & $-.13 * * *$ & $-.14 * * *$ & -.01 & $-.05 *$ & $-.38 * * *$ & $-.27 * * *$ & $.29 * * *$ & $.25 * * *$ \\
\hline Southern Europe & $.15^{* *}$ & $.09 *$ & $-.22 * * *$ & $-.14 * * *$ & $-.13^{* *}$ & $-.15 * * *$ & $-.47 * * *$ & $-.30 * * *$ & $.28 * * *$ & $.19 * * *$ \\
\hline Middle East & $.13 * *$ & .02 & $-.19 * * *$ & $-.13 * *$ & $-.12 * *$ & $-.12 * *$ & $-.37 * * *$ & $-.26 * * *$ & $.27 * * *$ & $.21 * * *$ \\
\hline Africa & $.11 *$ & .08 & $-.27 * * *$ & $-.17 * *$ & $-.23 * * *$ & $-.18 * *$ & $-.22 * * *$ & $-.18 * *$ & $.15^{* *}$ & $.25 * * *$ \\
\hline Oceania & .09 & $.15 * *$ & -.10 & $-.15 * * *$ & -.08 & -.03 & $-.50 * * *$ & $-.34 * * *$ & $.27 * * *$ & $.30 * * *$ \\
\hline South/Southeast Asia & .06 & .11 & -.08 & $-.12 *$ & -.09 & $-.14 * *$ & $-.35 * * *$ & $-.20 * * *$ & $.26 * * *$ & $.30 * * *$ \\
\hline East Asia & $.22 * * *$ & $.09 *$ & -.05 & $-.13 * *$ & .00 & -.05 & $-.30 * * *$ & $-.38 * * *$ & $.25 * * *$ & $.25 * * *$ \\
\hline Worldwide sample & $.16^{* * * *}$ & $.10 * * *$ & $-.12 * * *$ & $-.13 * * *$ & $-.05 * * *$ & $-.08 * * *$ & $-.38 * * *$ & $-.29 * * *$ & $.26 * * *$ & $.25 * * *$ \\
\hline
\end{tabular}

Note. Correlations represent partial correlations controlling for individual nation within region.

$* p<.05$. ** $p<.01 . \quad * * * p<.001$. 
Table 12

Are Men and Women Who More Successfully Attempt Mate Poaching More Open, Sexy, Unfaithful, Unrestrained, and Erotophilic Than Those Who Attempt but Fail?

\begin{tabular}{|c|c|c|c|c|c|c|c|c|c|c|}
\hline \multirow[b]{2}{*}{ World region } & \multicolumn{2}{|c|}{ Openness } & \multicolumn{2}{|c|}{$\begin{array}{c}\text { Sexual } \\
\text { attractiveness }\end{array}$} & \multicolumn{2}{|c|}{$\begin{array}{c}\text { Relationship } \\
\text { exclusivity }\end{array}$} & \multicolumn{2}{|c|}{ Sexual restraint } & \multicolumn{2}{|c|}{$\begin{array}{l}\text { Erotophilic } \\
\text { disposition }\end{array}$} \\
\hline & Men & Women & Men & Women & Men & Women & Men & Women & Men & Women \\
\hline North America & $.09 * *$ & .05 & $.35 * * *$ & $.23 * * *$ & $-.15 * * *$ & $-.16 * * *$ & $-.23 * * *$ & $-.27 * * *$ & $.12 * * *$ & $.14^{* * * *}$ \\
\hline South America & .09 & -.02 & $.23 * * *$ & .05 & -.04 & .04 & $-.14^{*}$ & $-.30 * * *$ & .00 & -.04 \\
\hline Western Europe & -.02 & .05 & $.25 * * *$ & $.30 * * *$ & $-.14 * * *$ & $-.16^{* * *}$ & $-.22 * * *$ & $-.22 * * *$ & $.16^{* * *}$ & $.15^{* * * *}$ \\
\hline Eastern Europe & $.20 * * *$ & $.19 * * *$ & $.28 * * *$ & $.26 * * *$ & $-.13 * * *$ & $-.14 * * *$ & $-.13^{* * *}$ & $-.20 * * *$ & $.14 * * *$ & $.12^{* *}$ \\
\hline Southern Europe & $.22 * * *$ & $.27 * * *$ & $.44 * * *$ & $.34 * * *$ & $-.18 * *$ & -.08 & $-.15^{*}$ & $-.30 * * *$ & .10 & $.18^{* *}$ \\
\hline Middle East & $.22 * * *$ & .15 & $.23 * * *$ & $.20 *$ & $-.13^{*}$ & -.15 & $-.23 * * *$ & $-.37 * * *$ & $.16^{*}$ & $.26^{* *}$ \\
\hline Africa & $.19 *$ & -.05 & $.31 * * *$ & $.27 *$ & -.01 & $-.22 *$ & -.07 & .03 & .05 & $.32 * *$ \\
\hline Oceania & $.19 *$ & $.10 *$ & $.20 * *$ & $.25 * * *$ & $-.17 *$ & $-.19 *$ & -.01 & $-.20 * *$ & .03 & $.30 * * *$ \\
\hline South/Southeast Asia & $.19 *$ & $.29 * *$ & $.31 * * *$ & $.38 * * *$ & $-.17 *$ & -.20 & -.10 & $-.29 * *$ & .11 & $.32 * *$ \\
\hline East Asia & $.27 * * *$ & $.32 * *$ & $.20 *$ & $.43 * * *$ & $-.28 * * *$ & $-.23 *$ & $-.25 * *$ & $-.21 *$ & $.23 * *$ & $.31 * *$ \\
\hline Worldwide sample & $.17 * * *$ & $.12 * * *$ & $.30 * * *$ & $.27 * * *$ & $-.14 * * *$ & $-.15 * * *$ & $-.17 * * *$ & $-.26 * * *$ & $.13 * * *$ & $.17 * * *$ \\
\hline
\end{tabular}

Note. Correlations represent partial correlations controlling for individual nation within region.

$* p<.05$. ** $p<.01$. **** $p<.001$.

another's partner are somewhat consistent across cultures. People who reported having poaching success score higher on openness to experience and sexual attractiveness, and they score lower on relationship exclusivity. There was also a tendency for successful mate poachers to describe themselves as sexually unrestrained. Among women, but not men, it was common across regions for successful mate poachers to be erotophilic in disposition. The finding that people who are unfaithful and erotophilic tend not only to practice mate poaching but also to be successful at it when attempted, suggests that these two traits are integral to the psychology of mate poaching. The finding that attractive individuals tend to be more successful at mate poaching demonstrates that some of the same processes of general romantic attraction may be operating in the context of mate poaching. For women seeking short-term mates, and for men seeking long-term or short-term mates, physical attractiveness is highly desired (Buss \& Schmitt, 1993; Schmitt \& Buss, 1996). Thus, the psychological adaptations of women and men that influence general mate selection appear to be relevant to mate poaching as well.

In sum, the psychological traits of successful mate poachers were both universal and, in some ways, region-specific. Successful mate poachers tended to be open and sexually attractive, as well as unfaithful to their own relationship partners. Those who were successful in poaching also tended to be sexually unrestrained, and erotophilia was pronounced among women. Several of these crossculturally pervasive linkages of personality, sexuality, and mate poaching fell short of statistical significance, but the gross pattern of correlations was similar across all 10 world regions.

What type of person is a common target of mate poachers? Schmitt and Buss (2001) found that people who receive matepoaching attempts (i.e., those who are common targets of mate poachers) described themselves as especially extraverted and open to experience. As displayed in Table 13, we confirmed across world regions that people who receive more poaching attempts

Table 13

Are Men and Women Who More Often Receive Mate-Poaching Attempts More Extraverted, Open to Experience, Sexually Attractive, Unfaithful, and Erotophilic Than Others?

\begin{tabular}{|c|c|c|c|c|c|c|c|c|c|c|}
\hline \multirow[b]{2}{*}{ World region } & \multicolumn{2}{|c|}{ Extraversion } & \multicolumn{2}{|c|}{ Openness } & \multicolumn{2}{|c|}{$\begin{array}{c}\text { Sexual } \\
\text { attractiveness }\end{array}$} & \multicolumn{2}{|c|}{$\begin{array}{l}\text { Relationship } \\
\text { exclusivity }\end{array}$} & \multicolumn{2}{|c|}{$\begin{array}{l}\text { Erotophilic } \\
\text { disposition }\end{array}$} \\
\hline & Men & Women & Men & Women & Men & Women & Men & Women & Men & Women \\
\hline North America & $.22 * * *$ & $.18 * * *$ & $.06 *$ & $.07 * * *$ & $.40 * * *$ & $.33 * * *$ & $-.31 * * *$ & $-.19 * * *$ & $.20 * * *$ & $.19 * * *$ \\
\hline South America & $.15^{* *}$ & $.13^{*}$ & $.18 * *$ & $.15^{* *}$ & $.21 * * *$ & $.15^{* *}$ & $-.18 * * *$ & $-.19 * * *$ & $.11 *$ & .10 \\
\hline Western Europe & $.25 * * *$ & $.21 * * *$ & $.09 * *$ & $.17 * * *$ & $.33 * * *$ & $.37 * * *$ & $-.29 * * *$ & $-.25 * * *$ & $.21 * * *$ & $.26 * * *$ \\
\hline Eastern Europe & $.19 * * *$ & $.17 * * *$ & $.12 * * *$ & $.16^{* * * *}$ & $.29 * * *$ & $.29 * * *$ & $-.28 * * *$ & $-.19 * * *$ & $.20 * * *$ & $.21 * * *$ \\
\hline Southern Europe & $.24 * * *$ & $.25 * * *$ & $.16^{* *}$ & .17 *** & $.24 * * *$ & $.34 * * *$ & $-.25 * * *$ & $-.22 * * *$ & $.23 * * *$ & $.20 * * *$ \\
\hline Middle East & $.22 * * *$ & $.12 * *$ & .05 & $.23 * * *$ & $.31 * * *$ & $.34 * * *$ & $-.22 * * *$ & $-.29 * * *$ & $.22 * * *$ & $.22 * * *$ \\
\hline Africa & $.19 * * *$ & $.16^{* *}$ & $.17 * * *$ & .06 & $.24 * * *$ & $.29 * * *$ & $-.10^{*}$ & .05 & $.14^{* *}$ & $.14^{*}$ \\
\hline Oceania & $.19 * * *$ & $.25 * * *$ & $.21 * * *$ & .07 & $.49 * * *$ & $.42 * * *$ & $-.31 * * *$ & $-.25 * * *$ & $.23 * * *$ & $.32 * * *$ \\
\hline South/Southeast Asia & -.03 & $.14 *$ & .01 & .11 & $.20 * * *$ & $.22 * * *$ & $-.14 *$ & -.02 & .11 & $.14^{*}$ \\
\hline East Asia & $.17 * * *$ & $.13 * *$ & .08 & $.17 * * *$ & $.19 * * *$ & $.26 * * *$ & $-.24 * * *$ & $-.21 * * *$ & $.17 * * *$ & $.17 * * *$ \\
\hline Worldwide sample & $.21 * * *$ & $.20 * * *$ & $.11 * * *$ & $.14 * * *$ & $.32 * * *$ & $.32 * * *$ & $-.24 * * *$ & $-.17 * * *$ & $.19 * * *$ & $.21 * * *$ \\
\hline
\end{tabular}

Note. Correlations represent partial correlations controlling for individual nation within region.

$* p<.05$. *** $p<.01$. *** $p<.001$. 
tend to have an extraverted personality. Only men from South/ Southeast Asia failed to display this linkage. The relationship between receiving mate-poaching attempts and openness to experience was less consistent across regions, however. Mate-poaching targets were higher on openness in several "Western" cultures, corroborating the finding that those high in sensation-seeking, a trait corresponding to high levels of extraversion and openness to experience, are more susceptible to risky sexual behavior involving multiple sexual partnerships (Zuckerman, 1994). Male poachers in the Middle East, South/Southeast Asia, and East Asia, and female poachers in Africa, Oceania, and South/Southeast Asia, however, did not score significantly higher in openness.

Similar to the findings of Schmitt and Buss (2001), across all world regions, people who received frequent mate-poaching attempts described themselves as sexually attractive. This makes sense in that men and women often seek physical attractiveness in potential romantic partners (Buss, 1989; Schmitt \& Buss, 1996). Frequent targets of mate poachers also described themselves as sexually unfaithful. Apparently, mate poachers around the world are attuned to the probability of success when they choose poaching targets. Finally, targets of mate poaching described themselves as having an erotophilic disposition. Being willing to talk openly about sex and sexual deviance appear to be universal attractants to would-be mate poachers.

What type of person is successfully poached away? As displayed in Table 14, the psychological traits of people who reported they have been poached away from a past partner are not as consistent across regions as are the traits of mate poachers. Similar to the traits of mate poachers, those who have succumbed to poaching attempts tended to be disagreeable. These links were not significant for men or women in Western Europe or the Middle East, however. Contrary to the findings of Schmitt and Buss (2001), the correlation between low conscientiousness and going along with a mate-poaching attempt was nonsignificant for both men and women in South America, the Middle East, South/ Southeast Asia, and East Asia.

People who reported having succumbed to a mate-poaching attempt scored lower on relationship exclusivity than other people, a finding that provides universal convergent validity to the ARAS scale. People who reported succumbing to poachers also reported more erotophilia, across most cultures. Finally, Schmitt and Buss (2001) found that those who had gone along with a mate poach were lower on the Emotional Investment scale of Schmitt and Buss's (2000) Sexy Seven Measure of sexuality attributes. This pattern largely failed to replicate and was evident only in North America, among men from South America and Oceania and among women from South/Southeast Asia and East Asia.

In sum, the psychological profiles of mate poachers and matepoaching targets were similar across most cultures. Mate poachers tended to be extraverted and disagreeable, as well as unfaithful and erotophilic. Those who were common targets of poaching reported high levels of extraversion and openness and described themselves as sexually attractive, unfaithful, and erotophilic. These crossculturally pervasive linkages of personality, sexuality, and mate poaching suggest that the psychology of mate poaching has universal qualities that are not limited to North America's specific sexual culture.

\section{Hypothetical Links Between Culture and Mate Poaching}

Men's occurrence and prevalence of short-term mate-poaching attempts were positively correlated across world regions, $r(8)=$ $.92, p<.001$. Women's occurrence and prevalence of short-term mate-poaching attempts also were positively correlated, $r(8)=$ $.96, p<.001$, as were the magnitudes of sex differences in the occurrence and prevalence of short-term mate-poaching attempts, $r(8)=.84, p<.001$. We collapsed poaching indicators across sex and temporal context and created overall poaching scales for Poaching Attempts, Poaching Success, Poaching Received, and Poaching Succumbed. Again, most forms of mate poaching were highly correlated across cultures. The sociocultural criterion variables used in this study were largely unrelated, though GDP per capita and economic gender equity were significantly associated $r(8)=.73, p<.01$. The complete intercorrelation matrix of all predictor and criterion variables is available from David P. Schmitt.

Table 14

Are Men and Women Who More Often Succumb to Mate-Poaching Attempts More Disagreeable, Unconscientious, Unfaithful, Erotophilic, and Unloving Than Others?

\begin{tabular}{|c|c|c|c|c|c|c|c|c|c|c|}
\hline \multirow[b]{2}{*}{ World region } & \multicolumn{2}{|c|}{ Agreeableness } & \multicolumn{2}{|c|}{ Conscientiousness } & \multicolumn{2}{|c|}{$\begin{array}{l}\text { Relationship } \\
\text { exclusivity }\end{array}$} & \multicolumn{2}{|c|}{$\begin{array}{l}\text { Erotophilic } \\
\text { disposition }\end{array}$} & \multicolumn{2}{|c|}{$\begin{array}{l}\text { Emotional } \\
\text { investment }\end{array}$} \\
\hline & Men & Women & Men & Women & Men & Women & Men & Women & Men & Women \\
\hline North America & $-.08 *$ & $-.10 * * *$ & $-.13 * * *$ & $-.12 * * *$ & $-.43^{* * *} *$ & $-.30 * * *$ & $.18 * * *$ & $.16^{* * * *}$ & $-.08 * *$ & $-.05^{*}$ \\
\hline South America & $-.17 * *$ & .02 & -.02 & .02 & $-.21 * * *$ & $-.23 * * *$ & -.04 & .06 & $-.14^{*}$ & .10 \\
\hline Western Europe & -.03 & -.04 & $-.10^{* *}$ & $-.14 * * *$ & $-.43^{* * *}$ & $-.37 * * *$ & $.12 * * *$ & $.17 * * *$ & .02 & -.02 \\
\hline Eastern Europe & -.06 & $-.06^{*}$ & -.04 & $-.12 * * *$ & $-.29 * * *$ & $-.30 * * *$ & $.14 * * *$ & $.19 * * *$ & .01 & -.01 \\
\hline Southern Europe & $-.17 * *$ & $-.10 *$ & $-.14^{*}$ & $-.13 * *$ & $-.37 * * *$ & $-.17 * * *$ & $.21 * * *$ & .07 & -.01 & -.01 \\
\hline Middle East & -.08 & .00 & -.10 & .02 & $-.45 * * *$ & $-.17 * *$ & $.15 * *$ & $.12 *$ & -.08 & .02 \\
\hline Africa & $-.16^{* *}$ & $-.15^{*}$ & $-.13 *$ & $-.24 * * *$ & $-.26 * * *$ & $-.31 * * *$ & .10 & $.28 * * *$ & .05 & -.11 \\
\hline Oceania & $-.18 * *$ & -.11 & $-.16^{*}$ & -.02 & $-.47 * * *$ & $-.34 * * *$ & $.23 * * *$ & $.16^{* *}$ & $-.17 * *$ & -.03 \\
\hline South/Southeast Asia & $-.18 * *$ & -.02 & -.08 & -.07 & $-.41 * * *$ & $-.21 * *$ & $.29 * * *$ & $.17^{*}$ & $.16^{*}$ & $-.14^{*}$ \\
\hline East Asia & -.03 & $-.21 * *$ & .11 & -.13 & $-.35 * * *$ & $-.38 * * *$ & $.21 * *$ & $.30 * * *$ & -.07 & $-.23 * *$ \\
\hline Worldwide sample & $-.09 * * *$ & $-.08 * * *$ & $-.10 * * *$ & $-.11 * * *$ & $-.37 * * *$ & $-.31 * * *$ & $.15 * * *$ & $.16^{* * *}$ & -.02 & $-.03 * *$ \\
\hline
\end{tabular}

Note. Correlations represent partial correlations controlling for individual nation within region.

$* p<.05$. ** $p<.01$. *** $p<.001$. 


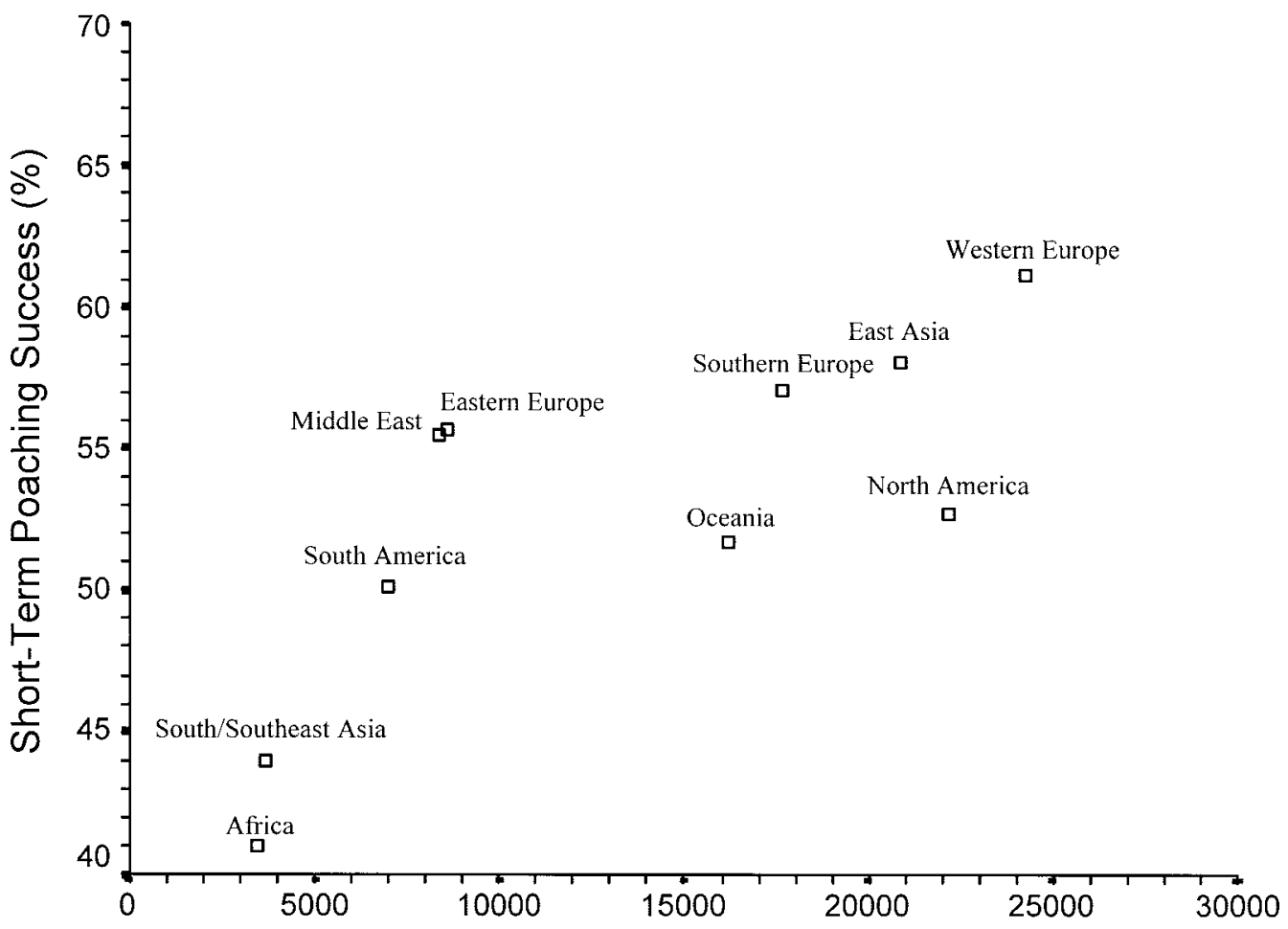

Gross Domestic Product (\$)

Figure 1. Gross domestic product (per capita) related to the occurrence of people succumbing to a short-term mate-poaching attempt across 10 world regions.

Hypothesis 1. According to sexual strategies theory (Buss \& Schmitt, 1993), men desire multiple mating partners more than women do, with men's strategy of short-term mate poaching serving as a key avenue for obtaining multiple partners. We found that proportionately more men than women across all regions of the ISDP had attempted short-term mate poaches (see Table 2) and that proportionately more men than women had succumbed to short-term mate-poaching attempts (see Table 8). There was some evidence that women report more success when they attempt short-term mate poaching (see Table 5), a further indication that men more easily succumb to short-term mate attempts than women do. There also were indications that women report receiving shortterm poaching attempts more than men do (see Table 7), although this finding was limited to North America, Western Europe, Eastern Europe, the Middle East, Africa, Oceania, and East Asia. Most findings from this study supported Hypothesis 1 and, by implication, the broader theory that men desire multiple mates more than women do (see Schmitt \& ISDP, 2003).

Hypothesis 2. According to strategic pluralism theory (Gangestad \& Simpson, 2000), biparental care of children and marital fidelity should become more important in regions with high environmental stress. One potential indicator of environmental stress is scarcity of resources. The frequency of short-term mate poaching, therefore, should be lower in regions with fewer resources. The per capita GDP for each world region was related to several indexes of short-term mate poaching. Although GDP was not related to at- tempts at short-term poaching, GDP was correlated positively with the regional occurrence of successful short-term mate poaching in women, $r(8)=.58, p<.05$. GDP also was significantly correlated with the rate at which women succumb to short-term poaching attempts, $r(8)=.75, p<.01$. In men, this latter relationship fell just short of statistical significance, $r(8)=.53, p=.057$. The prevalence of women succumbing to short-term mate poaches also was positively related to GDP, $r(8)=.73, p<.01$. After collapsing across men and women, the relationship between GDP and the occurrence of succumbing to short-term mate-poaching attempts reached statistical significance, $r(8)=.76, p<.01$. A scatterplot of this bivariate relationship across world regions is displayed in Figure 1. As predicted by strategic pluralism theory (Gangestad \& Simpson, 2000), it appears that men and women in cultural regions with fewer resources tend not to engage in successful short-term mate poaching. ${ }^{1}$

Women appeared to be slightly more affected by scarcity of resources, with sex differences in the occurrence of successful short-term mate poaching, $r(8)=-.56, p<.05$, and in succumbing to short-term mate poaching, $r(8)=-.57, p<.05$, decreasing as regional resources increased. The negative correlation between resources and sex differences in short-term poaching also was

\footnotetext{
${ }^{1}$ Tests for curvilinearity revealed no significant associations between predictors and criteria.
} 
evident in the occurrence, $r(8)=-.78, p<.01$, and prevalence, $r(8)=-.55, p<.05$, of self-reported poaching attempts. Thus, it appears that increased levels of resources lead to smaller sex differences in short-term poaching, primarily owing to the associated increase in women's short-term poaching.

We also related short-term mate-poaching experiences to the socioeconomic status of men and women within each of the 10 world regions of the ISDP. Of particular interest were the participants' reports of the socioeconomic status in which they were raised. As seen in Table 15, men who reported making more attempts at short-term poaching tended to come from a higher socioeconomic background, $r(6684)=.05, p<.001$. Although small in magnitude, this significant finding was present within the specific regions of North America, Western Europe, the Middle East, and Africa. This trend also was present among women, $r(9330)=.02, p<.05$, including within the specific regions of Southern Europe, South/Southeast Asia, and East Asia. As predicted, therefore, those with fewer resources tended to engage in less short-term mate poaching. Men's and women's rates of successful short-term poaching and reception of short-term poaching attempts, as well as men's succumbing to short-term poaching, also were significantly related to socioeconomic status in the predicted direction. Overall, these individual-level findings provide further support for Hypothesis 2 and for the broader theory of strategic pluralism (Gangestad \& Simpson, 2000).

Hypothesis 3. According to theories concerning human sex ratios (Pedersen, 1991), as the ratio of men to women becomes unbalanced in a culture, the pressure for finding a suitable mate becomes greater on the more populous sex. Thus, in regions with more women than men (with what is traditionally referred to as a low sex ratio), it was expected that women would be more likely to engage in mate poaching. We found this to be the case, with the occurrence of women's short-term, $r(8)=-.63, p<.05$, and long-term, $r(8)=-.62, p<.05$, mate-poaching attempts negatively correlating with the average sex ratio across world regions. We also found that the regional prevalence of women's short-term poaching attempts was negatively correlated with sex ratio. However, we did not find that men's mate poaching increased with sex ratio. Instead, men's poaching rates were negatively associated with sex ratio across most indexes of poaching. Contrary to sexratio theory, therefore, men in cultures with a surplus of men reported fewer poaching attempts and poaching successes. Figure 2 portrays the regional levels of long-term mate-poaching attempts (after collapsing across men and women) related to sex ratios across world regions. Overall, regardless of whether short-term or long-term poaching was considered, poaching rates tended to increase when the percentage of women increased across regions. As a result, sex-ratio theory was only partially confirmed in this study.

Hypothesis 4. According to social structural theory (Eagly \& Wood, 1999; Wood \& Eagly, 2002), women's greater access to political and economic power should be associated with smaller sex differences in sexuality. Several of the ISDP findings support this hypothesis. For example, sex differences in the occurrence of short-term mate-poaching attempts tended to be smaller in regions with greater gender equality, as assessed by the Gender Development Index, $r(8)=-.85, p<.001$. The relationship between gender equality and sex differences in mate poaching appeared to result primarily from women's increased poaching behavior in egalitarian regions. Men's mate-poaching experiences tended to decrease in some instances. For example, the prevalence of men's long-term poaching attempts was negatively correlated with gender egalitarianism, $r(8)=-.62, p<.05$. For women, long-term poaching attempts were positively correlated with gender egalitarianism, $r(8)=.45, p<.10$, though this association was only marginally significant.

Women's access to greater political power, as indexed by the percentage of women in parliament, was associated with increased poaching by women. Men's poaching, however, also increased with women's increased access to political power. For example, the occurrence of women's short-term poaching attempts was positively correlated with political equality, $r(8)=.72, p<.01$, as was the prevalence of short-term poaching attempts, $r(8)=.72$, $p<.01$. For men, the occurrence of short-term poaching attempts was positively correlated with political equality, $r(8)=.50, p<$ .10 , though again this association was only marginally significant.

Table 15

Prevalence of Short-Term Mate Poaching Related to Socioeconomic Status Across 10 World Regions

Short-term mate-poaching experiences

\begin{tabular}{|c|c|c|c|c|c|c|c|c|}
\hline \multirow[b]{3}{*}{ World region } & \\
\hline & \multicolumn{2}{|c|}{ Poaching attempts } & \multicolumn{2}{|c|}{ Poaching success } & \multicolumn{2}{|c|}{ Poaching received } & \multicolumn{2}{|c|}{ Poaching succumbed } \\
\hline & Men & Women & Men & Women & Men & Women & Men & Women \\
\hline North America & $.07 * *$ & .00 & $.07 *$ & .04 & .05 & .00 & $.09 * *$ & .01 \\
\hline South America & -.07 & .02 & .11 & -.08 & -.02 & .01 & -.06 & -.02 \\
\hline Western Europe & $.11 * * *$ & .01 & $.12 * * *$ & .01 & $.11 * * *$ & $.06^{*}$ & .04 & -.02 \\
\hline Eastern Europe & .06 & .02 & -.02 & .00 & .06 & .03 & -.02 & -.03 \\
\hline Southern Europe & .05 & $.14 * * *$ & .04 & $.14^{*}$ & .03 & $.10^{*}$ & .01 & .00 \\
\hline Middle East & $.09 *$ & -.08 & $.22 * *$ & -.11 & .07 & $-.09 *$ & .03 & .04 \\
\hline Africa & $.12 * *$ & .00 & $.11 *$ & $.15^{*}$ & $.10 * *$ & .06 & $.13^{* *}$ & -.06 \\
\hline Oceania & .09 & .05 & .05 & -.14 & .05 & .10 & -.03 & $-.14^{*}$ \\
\hline South/Southeast Asia & .12 & $.16^{* *}$ & .10 & .16 & .02 & $.16^{* *}$ & .13 & $.26 * *$ \\
\hline East Asia & .05 & $.08 *$ & .05 & .11 & $.09 *$ & $.08 *$ & -.02 & .03 \\
\hline Worldwide sample & $.05 * * *$ & $.02 *$ & $.10^{* * * *}$ & $.05 * * *$ & $.05 * * *$ & $.04 * * *$ & $.03^{*}$ & .02 \\
\hline
\end{tabular}

Note. Correlations represent partial correlations controlling for individual nation within region.

$* p<.05$. ** $p<.01$. **** $p<.001$. 


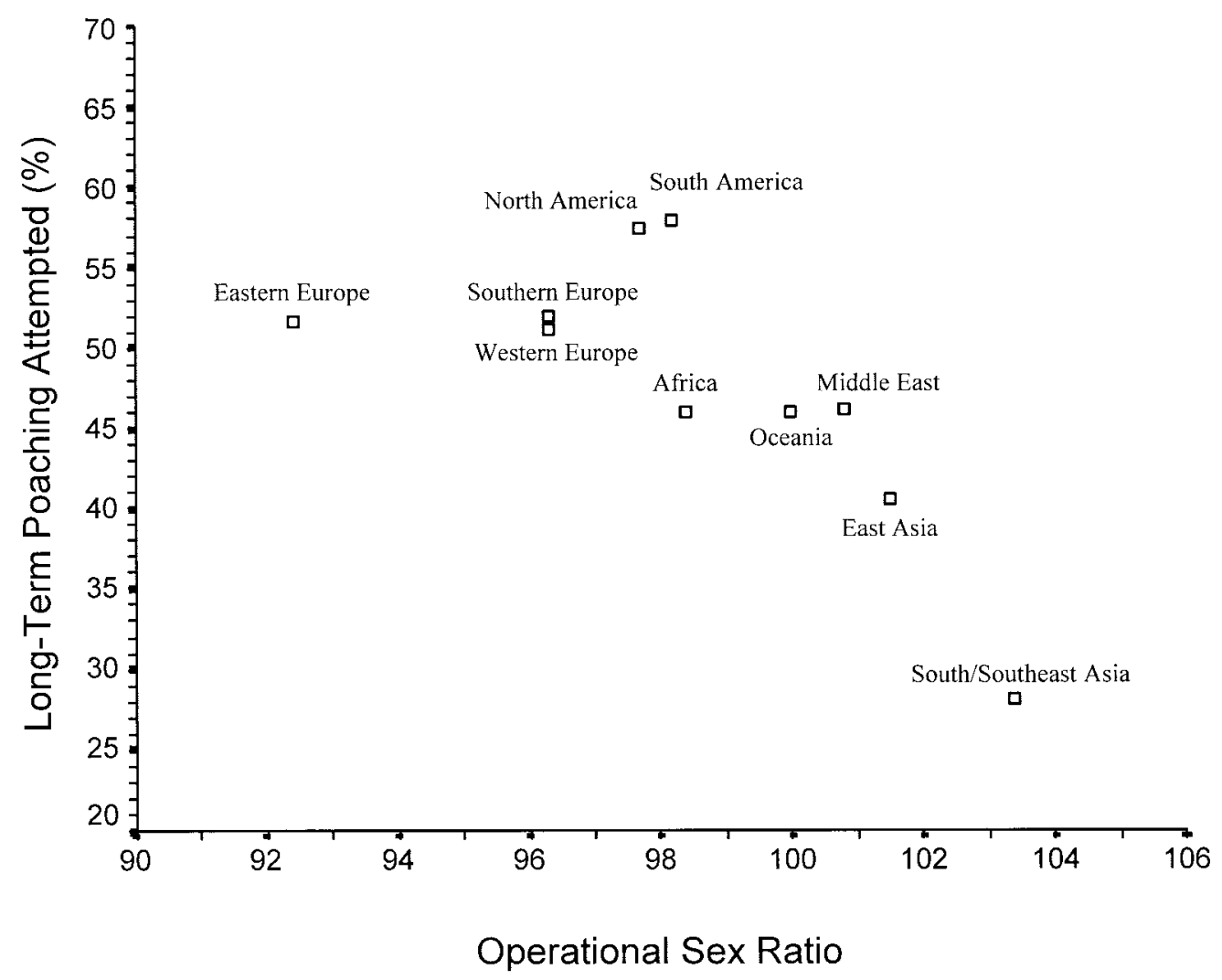

Figure 2. Operational sex ratio related to the percentage of people who have attempted to poach a long-term mate across 10 world regions.

Overall, social structural theory was largely supported in this study.

\section{Discussion}

Mate-poaching experiences can have important social consequences for all those involved, including retributional violence, social ostracism, cuckoldry, jealousy, and relationship dissolution (Schmitt \& Buss, 2001; Schmitt \& Shackelford, 2003). Unfortunately, mate poaching is often cloaked in secrecy, making it difficult to study with the research methods currently available to social scientists. Even so, the present findings-based on anonymous self-report surveys administered to 16,954 people around the world-yield three fundamental conclusions. First, mate poaching is a cultural universal, at least across the 10 world regions of the ISDP. Many people from North America, South America, Western Europe, Eastern Europe, Southern Europe, the Middle East, Africa, Oceania, South/Southeast Asia, and East Asia report that they have attempted, received, and occasionally succumbed to the experience of poaching. Second, mate poachers and their targets possess the same basic personality traits across all world regions, with extraversion, agreeableness, openness, and erotophilia serving as the primary correlates of mate poaching. Third, mate-poaching experiences are associated with aspects of culture in ways that support several evolutionary theories of human mating. Each of these findings, along with associated limitations, is addressed more fully below.

\section{Frequency of Mate Poaching}

Across the 10 world regions of the ISDP, around $60 \%$ of men and $40 \%$ of women admit that they have tried to poach someone else's partner, either for the purpose of having a short-term sexual relationship or for the purpose of forming a new long-term mating alliance. Among those who have attempted to poach, the occurrence of successful poaching was substantial (often over $80 \%$ ). The prevalence of short-term and long-term mate-poaching attempts only ranged from "rarely" to "seldom," but the prevalence rating of success among those who have attempted poaching centered on the midpoint (i.e., "moderate success") of the scales used in this study.

Nearly $70 \%$ of people report that someone has tried to poach them, and around $50 \%$ of those who have been tempted by a would-be mate poacher have succumbed to that attempt. Given that a single poaching attempt can cause significant discord in a romantic relationship and that merely one poaching success can result in severe social and reproductive consequences, the current findings suggest that the problem of mate poaching has farreaching relevance. Whether in the form of brief short-term desertions or permanent long-term defections, it appears that mate poaching is a culturally universal human experience, one that is undoubtedly related to the strong feelings of jealousy, rage, and betrayal that have coevolved as part of the human condition (Buss, 2000; Shackelford \& Buss, 1996; Shackelford et al., 2000). 
Mate poaching sometimes leads to positive outcomes as well. In almost every region we studied, around $10 \%$ of romantic relationships were the result of mate poaching, and around 3\% were the result of two people poaching one another out of their old relationships and into a new mateship. Mate poaching, it appears, can lead to the successful development of new romantic partnerships. How long these poaching-based relationships will last is an important question for future research. In this study, we can gain some insight into this question by examining the personal characteristics of mate poachers.

\section{Personality of Mate Poaching}

The personal characteristics of those who poach and those who are targets of poaching conform to a consistent pattern across most world regions. Those who attempt to poach another's partner are especially extraverted, disagreeable, unconscientious, unfaithful, and erotophilic. As documented in previous studies, mate poachers appear to possess certain personality traits (i.e., assertiveness combined with the tendency to be unempathetic) that are indicative of narcissism (see Foster et al., 2002) and may reflect a heritable or ecologically evoked orientation to short-term mating more generally (Bailey, Kirk, Zhu, Dunne, \& Martin, 2000; MacDonald, 1998; Rowe, 2002). Among those who attempt to poach, the most successful mate poachers are those who are open to experience, sexually attractive, unfaithful, and erotophilic. The finding that those with high sexual attractiveness are more successful would seem to confirm that the mate preferences involved in general romantic attraction (Buss \& Schmitt, 1993) are operative in the psychology of human mate poaching as well.

Common targets of mate poaching express high levels of extraversion, openness, attractiveness, unfaithfulness, and erotophilia. Those who succumb to mate poachers are particularly disagreeable, unconscientious, unfaithful, erotophilic and, in Western cultures, unloving. This heuristic guide to the psychology of mate poachers and those who are poached should be useful to future studies in which individual differences in mate poaching and their implications are more fully explored. As a whole, these results suggest that mate poaching is an important and, at least in some ways, psychologically distinct form of romantic attraction. It also can be concluded that, although mate poaching leads to new relationships, the personality traits of those who engage in and succumb to mate poaching (i.e., disagreeableness, unfaithfulness, and erotophilia) lead us to conclude that these new relationships may not be long lasting.

\section{Culture of Mate Poaching}

We tested four hypotheses about the cultural patterns and universals of human mate poaching. Hypothesis 1 was strongly supported. Proportionately more men than women pursue short-term mate poaching across all ISDP regions. This is true when assessed in terms of the occurrence and prevalence of short-term mate poaching. Men also disproportionately succumb to women's shortterm poaching attempts. Whether assessed with occurrence or prevalence rates, the ISDP findings confirm that men seek and go along with short-term mate poaching more than women do, precisely as predicted by sexual strategies theory (Buss \& Schmitt, 1993).
Two other findings provide support for Hypothesis 1. First, women tend to report receiving more short-term poaching attempts than men, though this sex difference is limited to prevalence rates in North America, Western Europe, Eastern Europe, the Middle East, Africa, and Oceania. Given the tendency for men to overperceive the sexual interests and intentions of women (Haselton \& Buss, 2000), this finding provides a reasonable level of support for Hypothesis 1. Second, women in several world regions report significantly more success than men do when pursuing short-term poaches. Again, this is not a universal finding and is limited to prevalence rates in the regions of North America, Western Europe, Eastern Europe, and Oceania. Overall, this portrait of short-term poaching confirms that men seek out short-term mateships more than women and buttresses the more general hypothesis that men possess psychological adaptations that give rise to the desire for multiple sexual partners (Buss \& Schmitt, 1993; Schmitt \& ISDP, 2003).

Hypothesis 2 was partially supported. Across some, but not all, measures of short-term mate poaching, regions with fewer resources tend to have lower rates of short-term mate poaching. These findings support the view that humans might possess environmentally sensitive adaptations that influence mating strategy. When in resource-poor environments, it appears that humans pursue more long-term, monogamous mating strategies. When in resource-rich environments, in contrast, short-term strategies that include mate-poaching behaviors are more common, a finding that fits with the functional view of strategic pluralism theory (Gangestad \& Simpson, 2000). Still, given the correlational methodology of the present investigation, this conclusion must be considered tentative. Future longitudinal studies showing shifts in poaching behavior that correspond with concurrent shifts in resources across cultures would bring much needed convergent support for this hypothesis.

The associations among environmental indicators and matepoaching behaviors in this study seem to run counter to some well-established findings of attachment researchers. Several studies have shown that children from poor, unstable, and high-stress home environments tend to develop insecure parent-child attachment styles (Belsky, 1999), attachment styles that presumably give rise to insecure romantic attachment orientations in adulthood (Belsky, Steinberg, \& Draper, 1991). These insecure adult attachments are thought to share many of the basic features of short-term mating strategies (Kirkpatrick, 1998), including earlier and more prolific reproduction (Chisholm, 1996). Thus, an attachment perspective would expect that people from resource-poor regions (i.e., low GDP) would exhibit more short-term mate poaching, not less as was evident in the current ISDP investigation.

A recent study by Barber (2003) may shed light on these conflicting pieces of evidence. Barber documented across 85 nations that national levels of GDP were negatively related to teen birth rates. Thus, resource-poor environments were associated with higher rates of early reproduction, precisely as predicted from the attachment perspective. However, resource-poor environments (i.e., lower levels of GDP) also were associated with lower nonmarital or single-mother birth rates. Thus, as cultural regions possessed greater resources, Barber (2003) found that rates of women giving birth without being married (i.e., more short-term mating) actually increased, precisely as predicted by strategic pluralism theory (Gangestad \& Simpson, 2000). An integrated 
explanation of these findings and those of the current study may reside in the idea that environmental resource levels affect different components of short-term mating strategies in different ways. The early reproduction component of short-term mating (e.g., high teen birth rates) appears to be activated or evoked by exposure to low-resource levels. The adult components of short-term mating (e.g., high single-parenthood and more prevalent short-term poaching) appear to be activated by high-resource levels. Future studies looking at these variables both within and across cultures, particularly those that study changes over time, will be needed to fully address this issue.

Hypothesis 3 received partial support (Pedersen, 1991). As the number of women outsizes the number of men across regions (i.e., low sex ratios), women are more likely to engage in mate poaching. This is true for both short-term and long-term poaching among women. As the number of men outsizes the number of women, however, men are not more likely to engage in mate poaching. Instead, men's poaching rates are negatively associated with sex ratio. Why does an excess of women, but not men, lead to more poaching by both sexes? One speculation is that shifts in sex ratio drive mating systems as a whole, not just the mating psychology of one sex. When women are abundant and men are a scarce resource, men may be able to command more promiscuity on the part of women, and the entire mating system (for both men and women) may shift toward promiscuity (Schmitt, 2003). Regardless of whether men's or women's short-term or long-term poaching is considered, mate poaching (a form of promiscuity) tends to increase overall when the percentage of women increases across regions. Barber (2003) found similar results with male-biased sex ratios correlating negatively with both teen birth rates and singleparent rates across 85 nations.

Hypothesis 4 was largely supported (Eagly \& Wood, 1999). As women's access to resources increases across regions, women's rates of short-term poaching increase and sex differences in shortterm mate poaching are reduced. In many cases, men's short-term poaching also increases, but to a lesser extent than women's. Women's greater access to political power is equally associated with increases in women and men's poaching-related behavior and, as a result, sex differences in poaching are generally unrelated to the prevalence of women in parliament across regions. Apparently, greater political gender equity does not always result in attenuated sex differences. Instead, it appears to accentuate both men and women's poaching-related behavior (see also Schmitt, 2003).

Overall, the influence of culture on human mate poaching appears to be profound. Although proportionately more men than women seek short-term mate poaches across all regions of the ISDP, this effect is tempered by several cultural factors. When in resource-rich environments, for example, both men and women tend to engage in more short-term mate poaching. When women gain access to greater resources, women especially tend to engage in more short-term mate poaching and, as a result, the magnitude of sex differences in seeking and succumbing to short-term poaches is attenuated (though never eliminated). Finally, when the number of women is greater than the number of men in a region, people tend to engage in long-term and short-term mate poaching at higher rates as the entire mating system moves toward sexual promiscuity.
In science, the most valued studies often are those that directly contrast competing theories and are able to rule out one hypothesis in favor of another. In the present study, the most consistent finding was that men more than women seek and succumb to short-term mate poaching across all regions of the ISDP. However, all theories of human mating subjected to testing in this study received at least some empirical support. As a result, we are left with the relatively unsatisfying conclusion that mate-poaching experiences are predictable from several theoretical perspectives, none of which is conspicuously superior to the others. Perhaps in future investigations, additional measures and variables can be used that will better determine whether one of these competing theories is superior to the others.

\section{Limitations and Future Research Directions}

This study is limited in several ways. Five particular concerns lead us to interpret our results with caution. First, the samples included in this study are mostly comprised of undergraduate students. A number of studies suggest that many undergraduates do form long-term mating relationships, with roughly $50 \%$ being in enduring relationships at any one point in time (Buss et al., 1992; Schmitt \& Buss, 2001). A case can be made that issues of mate poaching are more prevalent for young adults than for other samples. Future research nevertheless should explore matepoaching frequency and personality among older, more diverse, and more committed samples. A number of studies suggest that men are most jealous and vigilant about potential poachers when married to young and attractive women (Buss \& Shackelford, 1997), suggesting that young married couples might be an ideal sample to study issues of mate-poaching psychology. On the other hand, actual rates of infidelity appear to increase among women in the mid-30s (Baker \& Bellis, 1995), suggesting that sexual desertions (which may reflect successful short-term mate-poaching attraction) are more common in later stages of adulthood. Studies of different age samples could explore these important developmental and life span dimensions of the mate-poaching experience.

Second, participants were not asked about the quality or satisfaction of their previous or current relationships. It seems likely that the quality of romantic relationships would be a determining factor in making mate-poaching attempts (Schmitt \& Buss, 2001). The percentages of men and women who are in unsatisfying relationships, however, may vary cross-culturally with marriage customs, degree of matrilocality, and economic conditions. These extraneous factors, therefore, may be associated with the regional and sex differences found in the current study. Although the precise connections among these factors may be difficult to determine, it will be especially important for future investigations of mate poaching to assess the quality or satisfaction people have with their current relationships.

A third shortcoming of this study is that some samples may have been especially unrepresentative of their region. In the ISDP samples from Africa, for example, most participants were college students. College students are probably unrepresentative of African populations, perhaps more so than for other world regions. In addition, several nations from the full ISDP were not administered the mate-poaching questions from the ISDP survey. Nations such as Jordan, India, and Fiji would have added more variability to our regional database and improved the testing of evolutionary and 
social-role theories. Future research that includes larger and truly representative samples from a wider range of cultural regions is needed to more accurately relate United Nations databases to profiles of mate poaching.

A fourth limitation of the current study involves the region-level evaluation of the current set of hypotheses. Indeed, even the use of national indexes such as GDP and other United Nations indicators is less than ideal for testing many of the theories presented in this article. Although GDP certainly reflects some degree of environmental demand, it is not a measure of the demanding nature of environments, in situ. It is simply a regional average that may have only limited relationships with an individual participant's family history and socioeconomic condition. We did measure individual socioeconomic status and this was related in predictable ways to poaching behavior. However, we feel the current analyses should be considered merely a first step in theory testing and development concerning the patterns and universals of human mate poaching across cultures.

A final limitation of the current study is its reliance on selfreport methodology. When comparing the scores of different cultures on mate-poaching scales, any observed differences may be due not only to a real cultural disparity in some aspect of poaching, but also to inappropriate translations, biased sampling, or the nonidentical response styles of people from different cultures (Grimm \& Church, 1999). In this study, it was assumed that reported perceptions of mate poaching were reasonably veridical representations of actual mate-poaching experiences. The many universal personality correlates suggest that our key concepts were being similarly measured across languages. Fully establishing veridicality would be an extraordinarily difficult task, given that mate poaching is often conducted in secret, making observational studies almost impossible to conduct. Still, in-depth interviews of successful mate poachers, as well as those who have been lured by mate poaching, may be one step toward providing convergent evidence of the current results. Perhaps assessing mate-poaching reactions in laboratory experiments (e.g., Schmitt, Couden, \& Baker, 2001) or capitalizing on social psychological principles such as contrast effects (e.g., Kenrick, Neuberg, Zierk, \& Krones, 1994) would help to establish the validity of the sex and regional differences in mate poaching found in this study. Cross-cultural studies in which more specific poaching behaviors are assessed, such as whether people have kissed someone who was already in a relationship, would further allow for clearer measurement equivalence across cultures and languages. Although the current study is the broadest investigation ever undertaken to reveal this hidden side of human romance, the clandestine complexity of mate poaching leaves much work to be done.

\section{References}

Abbey, A. (1982). Sex differences in attributions for friendly behavior: Do males misperceive females' friendliness? Journal of Personality and Social Psychology, 32, 830-838.

Ashton, M. C., Lee, K., \& Paunonen, S. V. (2002). What is the central feature of extraversion?: Social attention versus reward sensitivity. Journal of Personality and Social Psychology, 83, 245-251.

Bailey, J. M., Kirk, K. M., Zhu, G., Dunne, M. P., \& Martin, N. G. (2000). Do individual differences in sociosexuality represent genetic or environmentally contingent strategies? Evidence from the Australian twin registry. Journal of Personality and Social Psychology, 78, 537-545.
Baker, R. R., \& Bellis, M. A. (1995). Human sperm competition. London: Chapman \& Hall.

Barash, D. P., \& Lipton, J. E. (2001). The myth of monogamy. New York: Freeman.

Barber, N. (2003). Paternal investment prospects and cross-national differences in single parenthood. Cross-Cultural Research, 37, 163-177.

Belsky, J. (1999). Modern evolutionary theory and patterns of attachment. In J. Cassidy \& P. R. Shaver (Eds.), Handbook of attachment (pp. 141-161). New York: Guilford Press.

Belsky, J., Steinberg, L., \& Draper, P. (1991). Childhood experience, interpersonal development, and reproductive strategy: An evolutionary theory of socialization. Child Development, 62, 647-670.

Benet-Martínez, V., \& John, O. P. (1998). Los Cinco Grandes across cultures and ethnic groups: Multitrait-multimethod analyses of the Big Five in Spanish and English. Journal of Personality and Social Psychology, 75, 729-750.

Birkhead, T. (2000). Promiscuity: An evolutionary history of sperm competition. Cambridge, MA: Harvard University Press.

Bleske, A. L., \& Shackelford, T. K. (2001). Poaching, promiscuity, and deceit: Combating mating rivalry in same-sex friendships. Personal Relationships, 8, 407-424.

Blumstein, P., \& Schwartz, P. (1983). American couples. New York: Morrow.

Brislin, R. W. (1980). Translation and content analysis of oral and written material. In H. C. Triandis \& J. W. Berry (Eds.), Handbook of crosscultural psychology (Vol. 1, pp. 389-444). Boston: Allyn \& Bacon.

Broude, G. J., \& Greene, S. J. (1976). Cross-cultural codes on twenty sexual attitudes and practices. Ethnology, 15, 409-438.

Brown, D. E. (1991). Human universals. New York: McGraw-Hill.

Buss, D. M. (1989). Sex differences in human mate preferences: Evolutionary hypotheses tested in 37 cultures. Behavioral and Brain Sciences, 12, $1-49$.

Buss, D. M. (2000). The dangerous passion. New York: Free Press.

Buss, D. M., Larsen, R., Westen, D., \& Semmelroth, J. (1992). Sex differences in jealousy: Evolution, physiology, and psychology. Psychological Science, 3, 251-255.

Buss, D. M., \& Schmitt, D. P. (1993). Sexual strategies theory: An evolutionary perspective on human mating. Psychological Review, 100, 204-232.

Buss, D. M., \& Shackelford, T. K. (1997). From vigilance to violence: Mate retention tactics in married couples. Journal of Personality and Social Psychology, 72, 346-361.

Cerda-Flores, R. M., Barton, S. A., Marty-Gonzalez, L. F., Rivas, F., \& Chakraborty, R. (1999). Estimation of nonpaternity in the Mexican population of Nuevo Leon: A validation study of blood group markers. American Journal of Physical Anthropology, 109, 281-293.

Chisholm, J. S. (1996). The evolutionary ecology of attachment organization. Human Nature, 7, 1-38.

Church, A. T. (2001). Personality measurement in cross-cultural perspective. Journal of Personality, 69, 979-1006.

Cohen, J. (1988). Statistical power analysis for the behavioral sciences (2nd ed.). Hillsdale, NJ: Erlbaum.

Cronk, L. (1999). That complex whole: Culture and the evolution of human behavior. Boulder, CO: Westview Press.

Daly, M., \& Wilson, M. (1988). Homicide. Hawthorne, NY: Aldine.

Eagly, A. H. (1987). Sex differences in social behavior: A social-role interpretation. Hillsdale, NJ: Erlbaum.

Eagly, A. H., \& Wood, W. (1999). The origins of sex differences in human behavior: Evolved dispositions versus social roles. American Psychologist, 54, 408-423.

Fisher, H. (1987). The four year itch. Natural History, 10, 22-29.

Fisher, W. A., Byrne, D., White, L. A., \& Kelley, K. (1988). Erotophobiaerotophilia as a dimension of personality. Journal of Sex Research, 25, $123-151$. 
Foley, R. (1996). The adaptive legacy of human evolution: A search for the environment of evolutionary adaptedness. Evolutionary Anthropology, 5, 194-203.

Foster, J. D., Shrira, I., Campbell, W. K., \& Stone, E. A. (2002, June). Mate poaching, narcissism, and empathy. Poster session presented at the 14th Annual Meeting of the Human Behavior and Evolution Society, New Brunswick, NJ.

Frayser, S. (1985). Varieties of sexual experience: An anthropological perspective. New Haven, CT: HRAF Press.

Gangestad, S. W. (2001). Adaptive design, selective history, and women's sexual motivations. In J. A. French, A. C. Kamil, \& D. W. Leger (Eds.), Evolutionary psychology and motivation (pp. 37-74). Lincoln: University of Nebraska Press.

Gangestad, S. W., \& Simpson, J. A. (2000). The evolution of human mating: Trade-offs and strategic pluralism. Behavioral and Brain Sciences, 23, 573-587.

Gangestad, S. W., \& Thornhill, R. (1997). Human sexual selection and developmental stability. In J. A. Simpson \& D. T. Kenrick (Eds.), Evolutionary social psychology (pp. 169-195). Mahwah, NJ: Erlbaum.

Gaulin, S. J. C. (1997). Cross-cultural patterns and the search for evolved psychological mechanisms. In G. R. Bock \& G. Cardew (Eds.), Characterizing human psychological adaptations (pp. 195-207). Chichester, England: Wiley.

Glass, S. P., \& Wright, T. L. (1985). Sex differences in type of extramarital involvement and marital dissatisfaction. Sex Roles, 12, 1101-1120.

Goldberg, L. R. (1992). The development of markers for the Big-Five factor structure. Psychological Assessment, 4, 26-42.

Graziano, W. G., \& Eisenberg, N. H. (1997). Agreeableness: A dimension of personality. In R. Hogan, J. Johnson, \& S. Briggs (Eds.). Handbook of personality psychology (pp. 795-824). San Diego, CA: Academic Press.

Greiling, H., \& Buss, D. M. (2000). Women's sexual strategies: The hidden dimension of short-term mating. Personality and Individual Differences, 28, 929-963.

Grimm, S. D., \& Church, A. T. (1999). A cross-cultural study of response biases in personality measures. Journal of Research in Personality, 33, 415-441.

Gross, M. R. (1996). Alternative reproductive strategies and tactics: Diversity within the sexes. Trends in Ecology and Evolution, 11, 92-98.

Grosskopf, D. (1983). Sex and the married woman. New York: Simon \& Schuster.

Guttentag, M., \& Secord, P. F. (1983). Too many women? The sex ratio question. Beverly Hills, CA: Sage.

Haselton, M. G., \& Buss, D. M. (2000). Error management theory: A new perspective on biases in cross-sex mind reading. Journal of Personality and Social Psychology, 78, 81-91.

Hogan, J., \& Ones, D. S. (1997). Conscientiousness and integrity at work. In R. Hogan, J. Johnson, \& S. Briggs (Eds.), Handbook of personality psychology (pp. 849-870). San Diego, CA: Academic Press.

Hrdy, S. B. (1981). The woman that never evolved. Cambridge, MA: Harvard University Press.

Kasser, T., \& Sharma, Y. S. (1999). Reproductive freedom, educational equality, and females' preference for resource-acquisition characteristics in mates. Psychological Science, 10, 374-377.

Kenrick, D. T., Neuberg, S. L., Zierk, K. L., \& Krones, J. M. (1994). Evolution and social cognition: Contrast effects as a function of sex, dominance, and physical attractiveness. Personality and Social Psychology Bulletin, 20, 210-217.

Kenrick, D. T., Sadalla, E. K., Groth, G., \& Trost, M. R. (1990). Evolution, traits, and the stages of human courtship: Qualifying the parental investment model. Journal of Personality, 58, 97-116.

Kirkpatrick, L. A. (1998). Evolution, pair-bonding, and reproductive strategies: A reconceptualization of adult attachment. In J. A. Simpson \&
W. S. Rholes (Eds.), Attachment theory and close relationships (pp. 353-393). New York: Guilford Press.

Laumann, E. O., Gagnon, J. H., Michael, R. T., \& Michaels, S. (1994). The social organization of sexuality. Chicago: University of Chicago Press.

Lee, R. B., \& Daly, R. (Eds.). (1999). The Cambridge encyclopedia of hunters and gatherers. Cambridge, England: Cambridge University Press.

Maccoby, E. E. (1998). The two sexes. Cambridge, MA: Harvard University Press.

MacDonald, K. B. (1998). Evolution, culture, and the Five-Factor Model. Journal of Cross-Cultural Psychology, 29, 119-149.

Macintyre, S., \& Sooman, A. (1991). Non-paternity and prenatal genetic testing. Lancet, 338, 869-871.

Moore, M. M. (1995). Courtship signaling and adolescents: "Girls just wanna have fun"? Journal of Sex Research, 32, 319-328.

Neel, J. V., \& Weiss, K. M. (1975). The genetic structure of a tribal population, the Yanomama Indians: XIII. Biodemographic studies. American Journal of Physical Anthropology, 42, 25-51.

Pasternak, B., Ember, C., \& Ember, M. (1997). Sex, gender, and kinship: A cross-cultural perspective. Upper Saddle, NJ: Prentice Hall.

Pedersen, F. A. (1991). Secular trends in human sex ratios: Their influence on individual and family behavior. Human Nature, 2, 271-291.

Philipp, E. E. (1973). Discussion: Moral, social, and ethical issues. In G. E. W. Wolstenholme \& D. W. Fitzsimons (Eds.), Law and ethics of A. I. D. and embryo transfer: Ciba Foundation Symposium 17 (pp. 663-666). London: Associate Scientific.

Rowe, D. C. (2002). On genetic variation in menarche and age at first sexual intercourse: A critique of the Belsky-Draper hypothesis. Evolution and Human Behavior, 23, 365-372.

Sasse, G., Müller, H., Chakraborty, R., \& Ott, J. (1994). Estimating the frequency of nonpaternity in Switzerland. Human Heredity, 44, 337343.

Schmitt, D. P. (2002). A meta-analysis of sex differences in romantic attraction: Do rating contexts affect tactic effectiveness judgments? British Journal of Social Psychology, 41, 387-402.

Schmitt, D. P. (2003). Sociosexuality from Argentina to Zimbabwe: A 48-nation study of sex, culture, and the dynamics of human mating. Manuscript submitted for publication.

Schmitt, D. P., Alcalay, L., Allensworth, M., Allik, J., Ault, L., Austers, I., et al. (in press). Patterns and universals of adult romantic attachment across 62 cultural regions: Are models of self and other pancultural constructs? Journal of Cross-Cultural Psychology.

Schmitt, D. P., \& Buss, D. M. (1996). Strategic self-promotion and competitor derogation: Sex and context effects on the perceived effectiveness of mate attraction tactics. Journal of Personality and Social Psychology, 70, 1185-1204.

Schmitt, D. P., \& Buss, D. M. (2000). Sexual dimensions of person description: Beyond or subsumed by the Big Five? Journal of Research in Personality, 34, 141-177.

Schmitt, D. P., \& Buss, D. M. (2001). Human mate poaching: Tactics and temptations for infiltrating existing mateships. Journal of Personality and Social Psychology, 80, 894-917.

Schmitt, D. P., Couden, A., \& Baker, M. (2001). The effects of sex and temporal context on feelings of romantic desire: An experimental evaluation of Sexual Strategies Theory. Personality and Social Psychology Bulletin, 27, 833-847.

Schmitt, D. P., \& International Sexuality Description Project. (2003). Universal sex differences in the desire for sexual variety: Tests from 52 nations, 6 continents, and 13 islands. Journal of Personality and Social Psychology, 85, 85-104.

Schmitt, D. P., \& Shackelford, T. K. (2003). Nifty ways to leave your lover: The tactics people use to entice and disguise the process of human mate poaching. Personality and Social Psychology Bulletin, 29, 10181035. 
Schmitt, D. P., Shackelford, T. K., \& Buss, D. M. (2001). Are men really more 'oriented' toward short-term mating than women? A critical review of research and theory. Psychology, Evolution and Gender, 3, 211-239.

Schmitt, D. P., Shackelford, T., Duntley, J., Tooke, W., \& Buss, D. M. (2001). The desire for sexual variety as a tool for understanding basic human mating strategies. Personal Relationships, 8, 425-455.

Shackelford, T. K. (1997). Perceptions of betrayal and the design of the mind. In J. A. Simpson \& D. T. Kenrick (Eds.), Evolutionary social psychology (pp. 73-108). Hillsdale, NJ: Erlbaum.

Shackelford, T. K., \& Buss, D. M. (1996). Betrayal in mateships, friendships, and coalitions. Personality \& Social Psychology Bulletin, 22, 1151-1164.

Shackelford, T. K., \& LeBlanc, G. J. (2001). Sperm competition in insects, birds, and humans: Insights from a comparative evolutionary perspective. Evolution and Cognition, 7, 194-202.

Shackelford, T. K., LeBlanc, G. J., \& Drass, E. (2000). Emotional reactions to infidelity. Cognition \& Emotion, 14, 643-659.

Shackelford, T. K., LeBlanc, G. J., Weekes-Shackelford, V. A., BleskeRechek, A. L., Euler, H. A., \& Hoier, S. (2002). Psychological adaptation to human sperm competition. Evolution and Human Behavior, 23, 123-138.

Smith, R. L. (1984). Human sperm competition. In R. L. Smith (Ed.), Sperm competition and the evolution of animal mating systems (pp. 601-659). New York: Academic Press.

Spector, P. E. (1992). Summated rating scale construction. Newbury Park, CA: Sage.

Symons, D. (1979). The evolution of human sexuality. New York: Oxford University Press.

Tennov, D. (1999). Love and limerence. Lanham, NY: Scarborough House.

Thiessen, D. (1994). Environmental tracking by females: Sexual lability. Human Nature, 5, 167-202.

Thompson, A. P. (1983). Extramarital sex: A review of the research literature. Journal of Sex Research, 19, 1-22.

Tooke, W., \& Camire, L. (1991). Patterns of deception in intersexual and intrasexual mating strategies. Ethology and Sociobiology, 12, 345-364.

Trivers, R. (1972). Parental investment and sexual selection. In B. Campbell (Ed.), Sexual selection and the descent of man: 1871-1971 (pp. 136-179). Chicago: Aldine.

United Nations Development Programme. (2001). Human development report 2001. New York: Oxford University Press.

United Nations Statistics Division. (2001). World population prospects: The 2000 revision: Volume 1. Comprehensive tables (United Nations Publication, Sales No. E. 01. XIII. 8). New York: United Nations.

Walters, S., \& Crawford, C. B. (1994). The importance of mate attraction for intrasexual competition in men and women. Ethology and Sociobiology, 15, 5-30.

Watson, D., \& Clark, L. A. (1997). Extraversion and its positive emotional core. In R. Hogan, J. Johnson, \& S. Briggs (Eds.), Handbook of personality psychology (pp. 767-793). San Diego, CA: Academic Press.

Wiederman, M. W. (1997). Extramarital sex: Prevalence and correlates in a national survey. The Journal of Sex Research, 34, 167-174.

Wiederman, M. W., \& Hurd, C. (1999). Extradyadic involvement during dating. Journal of Social and Personal Relationships, 16, 265-274.

Williams, G. C. (1966). Adaptation and natural selection. Princeton, NJ: Princeton University Press.

Williams, J. E., \& Best, D. L. (1990). Measuring sex stereotypes: A multination study (Rev. ed.). Newbury Park, CA: Sage.

Wood, W., \& Eagly, A. H. (2002). A cross-cultural analysis of the behavior of men and women: Implications for the origins of sex differences. Psychological Bulletin, 128, 699-727.

Zuckerman, M. (1994). Psychobiology of personality. New York: Cambridge University Press.
The 121 coauthors of this article include the following: Lidia Alcalay, Pontificia Universidad Católica de Chile, Chile; Jüri Allik, University of Tartu, Estonia; Alois Angleitner, University of Bielefeld, Germany; Lara Ault, University of Louisville; Ivars Austers, University of Latvia, Latvia; Kevin L. Bennett, University of New Mexico; Gabriel Bianchi, Slovak Academy of Sciences, Slovak Republic; Fredrick Boholst, University of San Carlos, Philippines; Mary Ann Borg Cunen, University of Malta, Malta; Johan Braeckman, Ghent University, Belgium; Edwin G. Brainerd, Jr., Clemson University; Leo Gerard A. Caral, University of San Carlos, Philippines; Gabrielle Caron, Université of Laval, Canada; Maria Martina Casullo, University of Buenos Aires, Argentina; Michael Cunningham, University of Louisville; Ikuo Daibo, Osaka University, Japan; Charlotte De Backer, Ghent University, Belgium; Eros De Souza, Illinois State University; Rolando DiazLoving, National Autonomous University of Mexico, Mexico; Gláucia Diniz, University of Brasilia, Brazil; Kevin Durkin, The University of Western Australia, Australia; Marcela Echegaray, University of Lima, Peru; Ekin Eremsoy, Bogaziçi Üniversitesi, Turkey; Harald A. Euler, University of Kassel, Germany; Ruth Falzon, University of Malta, Malta; Maryanne L. Fisher, York University, Canada; Dolores Foley, University of Queensland Australia; Douglas P. Fry, Åbo Akademi University, Finland; Sirpa Fry, Åbo Akademi University, Finland; M. Arif Ghayur, Al-Akhawayn University, Morocco; Debra L. Golden, University of Hawaii at Manoa; Karl Grammer, Ludwig-Boltzmann-Institute for Urban Ethology, Austria; Liria Grimaldi, University of Catania, Italy; Jamin Halberstadt, University of Otago, New Zealand; Shamsul Haque, University of Dhaka, Bangladesh; Dora Herrera, University of Lima, Peru; Janine Hertel, Technische Universität Chemnitz, Germany; Heather Hoffmann, Knox College; Danica Hooper, University of Queensland, Australia; Zuzana Hradilekova, Comenius University, Slovak Republic; Jasna Hudek-Kene-evi, University of Rijeka, Croatia; Jas Jaafar, University of Malaya, Malaysia; Margarita Jankauskaite, Vilnius University, Lithuania; Heidi Kabangu-Stahel, Centre d'Enseignement les Gazelles, Democratic Republic of the Congo; Igor Kardum, University of Rijeka, Croatia; Brigitte Khoury, American University of Beirut, Lebanon; Hayrran Kwon, Kwangju Health College, Republic of Korea; Kaia Laidra, University of Tartu, Estonia; Anton-Rupert Laireiter, Institute of Psychology, University of Salzburg, Austria; Dustin Lakerveld, University of Utrecht, the Netherlands; Ada Lampert, The Ruppin Institute, Israel; Maryanne Lauri, University of Malta, Malta; Marguerite Lavallée, Université of Laval, Canada; Suk-Jae Lee, National Computerization Agency, Republic of Korea; Luk Chung Leung, City University of Hong Kong, China; Kenneth D. Locke, University of Idaho; Vance Locke, The University of Western Australia, Australia; Ivan Luksik, Slovak Academy of Sciences, Slovak Republic; Ishmael Magaisa, University of Zimbabwe, Zimbabwe; Dalia Marcinkeviciene, Vilnius University, Lithuania; André Mata, University of Lisbon, Portugal; Rui Mata, University of Lisbon, Portugal; Barry McCarthy, University of Central Lancashire, England; Michael E. Mills, Loyola Marymount University; Nhlanhla J. Mkhize, University of Natal, South Africa; João Moreira, University of Lisbon, Portugal; Sérgio Moreira, University of Lisbon, Portugal; Miguel Moya, University of Granada, Spain; M. Munyae, University of Botswana, Botswana; Patricia Noller, University of Queensland, Australia; Adrian Opre, Babes Bolyai University, Romania; Alexia Panayiotou, 
University of Cyprus, Cyprus; Nebojsa Petrovic, University of Belgrade, Serbia; Karolien Poels, Ghent University, Belgium; Miroslav Popper, Slovak Academy of Sciences, Slovak Republic; Maria Poulimenou, KPMG Kyriacou Counsultants SA, Greece; Volodymyr P'yatokha, Volyn Regional Hospital, Ukraine; Michel Raymond, Université de Montpellier II, France; Ulf-Dietrich Reips, Universität Zürich, Switzerland; Susan E. Reneau, University of Alabama; Sofia Rivera-Aragon, National Autonomous University of Mexico, Mexico; Wade C. Rowatt, Baylor University; Willibald Ruch, Queens University Belfast, Northern Ireland; Velko S. Rus, University of Ljubljana, Slovenia; Marilyn P. Safir, University of Haifa, Israel; Sonia Salas, Universidad de La Serena, Chile; Fabio Sambataro, University of Catania, Italy; Kenneth N. Sandnabba, Åbo Akademi University, Finland; Marion K. Schulmeyer, Universidad Privada de Santa Cruz de la Sierra, Bolivia; Astrid Schütz, Technische Universität Chemnitz, Germany; Tullio Scrimali, University of Catania, Italy; Todd K. Shackelford, Florida Atlantic University; Phillip R. Shaver, University of California-Davis; Francis Sichona, University of Dar es Salaam, Tanzania; Franco Simonetti, Pontificia Universidad Católica de Chile, Chile; Tilahun Sineshaw, Ramapo College of New Jersey; R. Sookdew, University of Natal, South Africa; Tom Speelman, Ghent University, Belgium; Spyros Spyrou, Cyprus College, Cyprus; H. Canan Sümer, Middle East Technical University, Tur- key; Nebi Sümer, Middle East Technical University, Turkey; Marianna Supekova, Slovak Academy of Sciences, Slovak Republic; Tomasz Szlendak, Nicholas Copernicus University, Poland; Bert Timmermans, Vrije Universiteit, Belgium; William Tooke, SUNY-Plattsburgh; Ioannis Tsaousis, University of the Aegean, Greece; F. S. K. Tungaraza, University of Dar es Salaam, Tanzania; Frank Van Overwalle, Vrije Universiteit Brussel, Belgium; Griet Vandermassen, Ghent University, Belgium; Tim Vanhoomissen, Vrije Universiteit Brussel, Belgium; Ine Vanwesenbeeck, Netherlands Institute of Social Sexological Research, the Netherlands; Paul L. Vasey, University of Lethbridge, Canada; João Verissimo, University of Lisbon, Portugal; Martin Voracek, University of Vienna Medical School, Austria; Wendy W. N. Wan, University of Hong Kong, China; Ta-Wei Wang, National Changhua University of Education, Taiwan; Peter Weiss, Charles University, Czech Republic; Andik Wijaya, Couple Clinic Indonesia, Surabaya, Indonesia; Liesbeth Woertman, Utrecht University, the Netherlands; Gahyun Youn, Chonnam National University, Republic of Korea; and Agata Zupanèiè, University of Ljubljana, Slovenia.

Received November 6, 2002 Revision received November 4, 2003 Accepted November 6, 2003

\section{Low Publication Prices for APA Members and Affiliates}

Keeping you up-to-date. All APA Fellows, Members, Associates, and Student Affiliates receive-as part of their annual dues-subscriptions to the American Psychologist and APA Monitor. High School Teacher and International Affiliates receive subscriptions to the APA Monitor, and they may subscribe to the American Psychologist at a significantly reduced rate. In addition, all Members and Student Affiliates are eligible for savings of up to $60 \%$ (plus a journal credit) on all other APA journals, as well as significant discounts on subscriptions from cooperating societies and publishers (e.g., the American Association for Counseling and Development, Academic Press, and Human Sciences Press).

Essential resources. APA members and affiliates receive special rates for purchases of APA books, including the Publication Manual of the American Psychological Association, and on dozens of new topical books each year.

Other benefits of membership. Membership in APA also provides eligibility for competitive insurance plans, continuing education programs, reduced APA convention fees, and specialty divisions.

More information. Write to American Psychological Association, Membership Services, 750 First Street, NE, Washington, DC 20002-4242. 